\title{
Numerical Investigation of the Flow Angularity Effects of the NASA Langley UPWT on the Ares I DAC1 0.01-Scale Model
}

\author{
Henry C. Lee* \\ ELORET Corp., Moffett Field, CA 94035
}

\author{
Goetz H. Klopfer ${ }^{\dagger}$ and Jeff T. Onufer ${ }^{\ddagger}$ \\ NASA Ames Research Center, Moffett Field, CA 94035
}

\begin{abstract}
Investigation of the non-uniform flow angularity effects on the Ares I DAC-1 in the Langley Unitary Plan Wind Tunnel are explored through simulations by OVERFLOW. Verification of the wind tunnel results are needed to ensure that the standard wind tunnel calibration procedures for large models are valid. The expectation is that the systematic error can be quantified, and thus be used to correct the wind tunnel data. The corrected wind tunnel data can thenn be used to quantify the CFD uncertainties.
\end{abstract}

\section{Nomenclature}

$\alpha \quad$ angle of attack, degrees $\left({ }^{\circ}\right)$

$\alpha_{\text {up }} \quad$ flow angularity correction on angle of attack, degrees $\left(^{\circ}\right)$

AOA angle of attack

$C_{N} \quad$ force coefficient in normal direction

$C_{A} \quad$ force coefficient in axial direction

$C_{m y} \quad$ pitching moment coefficient in y direction

$C_{\text {tun }} \quad$ coefficients corresponding to tunnel runs

$C_{n t} \quad$ coefficients corresponding to free air runs

$A_{\text {ref }} \quad$ reference area

CFD computational fluid dynamics

$C_{N} \quad$ normal force coefficient $\left(F_{N} / q A_{r e f}\right)$

OVERFLOW Navier-Stokes computational fluid dynamics solver

UPWT Unitary Plan Wind Tunnel (Langley)

Note: To make this document ITAR free, ITAR sensitive figures have had their scales removed, and data tables have had their values scaled by an arbitrary number.

\section{Introduction}

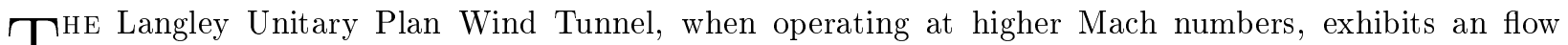
1 angularity angle upwards of $1.5^{\circ}$, according to the tunnel calibration report. ${ }^{1}$ As a result, large models such as the 0.01-scale model of the Ares I DAC1 experience a considerable amount of (potentially nonuniform) flow angularity over the length of the model. This can result in a different angle of attack (AOA) offset than determined by the standard wind tunnel data reduction procedures, introducing an unaccounted bias error into the data. Thus, verification of the wind tunnel results is needed to ensure that the standard calibration procedures are still appropriate for such large models and to quantify bias errors in the Ares 1 DAC-1 data.

OVERFLOW, a Navier-Stokes computational fluid dynamics (CFD) solver, can be used to validate the data obtained from the wind tunnel tests. Typically this is not done due to the unknown errors and

*Aerospace Engineer, Advanced Supercomputing Division, MS 258-2; Henry.C.Lee@nasa.gov.

$\dagger$ †erospace Engineer, Advanced Supercomputing Division, MS 258-2; Goetz.H.Klopfer@nasa.gov.

$\ddagger$ Aerospace Engineer, Advanced Supercomputing Division, MS 258-2; Jeffrey.T.Onufer.gov. 
uncertainties in the CFD data. Traditionally wind tunnel data are used to validate and determine the uncertainty of the CFD data. The uncertainty and accuracy of the wind tunnel data are estimated by multiple wind tunnel runs and tunnel-to-tunnel comparisons. However since wind tunnel tests and numerical simulations of the full Navier-Stokes equations are expensive, an attempt should be made to extract as much information as possible and to assess the accuracy and uncertainty of both. In this study CFD is used to assess the accuracy and uncertainty of the wind tunnel data by avoiding the issue of unknown accuracy and uncertainty of the CFD data. The expectation is that much of the systematic error can be quantified and thus can be used to correct the wind tunnel data. The corrected wind tunnel data can then be used to quantify the CFD error and uncertainties.

In this study, simulations of a simplified model (Ares I DAC-1) in the presence of simulated wind tunnel flow are performed at select angles of attack to determine the flow angularity effects on the AOA and other flow non-uniformities in the test section, to examine how well the solution performs after correcting for the effective flow angularities, and to verify the accuracy of the correction.

\section{Overview}

The goal of the present work is to run simulations of the Ares I DAC- 1 model at 4 different angles of attack, simulating the wind tunnel tests. Simulations of the model in the test section of the wind tunnel are run at $\pm 2^{\circ}$ to determine the effective flow angularities by finding the AOA where $C_{N}=0$. The model is also run at $\pm 7^{\circ}+\alpha_{\text {up }}$. These are called the correct wind tunnel simulations. The corrected results will be compared to the $+7^{\circ}$ free air run. The free air cases are considered to be the "true" results and the deviation of the corrected wind tunnel simulations from the free air simulations are due to the flow angularity and other test section flow non-uniformities. The data reduction procedure used for the wind tunnel data is applied to the wind tunnel simulation data. The values of the deviations will show the accuracy of the corrections. All of the numerical results reported in this work are produced with OVERFLOW 2.0aa. ${ }^{2,3}$

The entry section of the UPWT is simulated to obtain a much more representative flow state at the inlet station of the test section. Inflow conditions into the throat are set such that the static/stagnation conditions match the calibration report. For simulations involving test section 2, some smoothing is applied to the upper wall to aid convergence.

\section{Geometry}

The model tested is the 0.01-scale DAC1 as shown in Figure 1. However, all the values, including the Reynolds number, for the OVERFLOW simulation are scaled up to full scale. The reason for doing this is the original computations for the DAC1 configuration are performed at full scale, and that same grid system is used for the current simulations. The vehicle is placed such that the tip of the abort tower is at $\mathrm{x}=916.973$ in. when at $0^{\circ} \mathrm{AOA}$, which translates to about $0.76 \mathrm{ft}$ downstream of the test section inlet $(\mathrm{x}=0.0 \mathrm{in}$.) in the UPWT. The geometry (including the rocket and sting) is inserted into the tunnel, and the point of rotation is held constant ( $\mathrm{x}_{\text {rotation }}=5348.186$ in.). The test section modeled in the simulation is also scaled to 1 , making the $4 \times 4$ test section $400 \times 400 \mathrm{ft}$. Figure 2 shows the numerical model of the vehicle inside the tunnel, and Figure 3 shows a longitudinal (in the symmetry plane) cut.

The model used for this simulation is the DAC1 vehicle analyzed previously. It is an axisymmetric body with the stiffener and kick rings on the booster as well as the LAS motors on the escape tower removed. The grid system consists of five zones. The first is a cap grid starting from the very tip of the rocket extending upstream with a very high resolution to resolve the stagnation point at the tip. The second grid is the tower grid system. The third grid includes the overall body of the rocket up to the end of the first solid rocket booster. The fourth grid includes the tail end of the booster with the aft skirt. The fifth grid is a simple cylinder modeling the sting. All of these grids are stretched grids with tight spacing near the body and coarsening as it extents radially outward. The test section grids are modeled using data from Reference 1, and these grids consist of two zones, a wall-normal stretched polar grid extending from the walls into the

test section, and a core grid to remove the polar singularity of the wall grid. Table 1 outlines the number of grid points in each zone. 


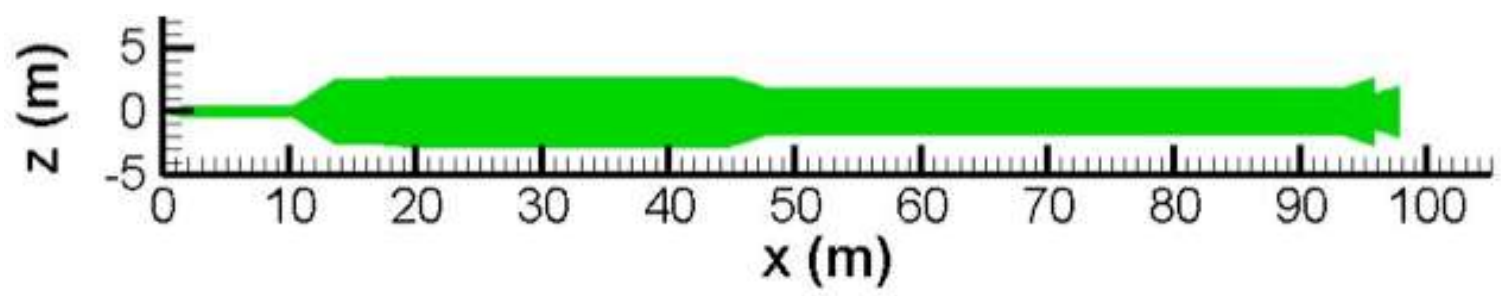

Figure 1: DAC1 Configuration shown with the model coordinate system. The tunnel coordinate system origin is $916 \mathrm{in}$. upstream of the model coordinate system origin

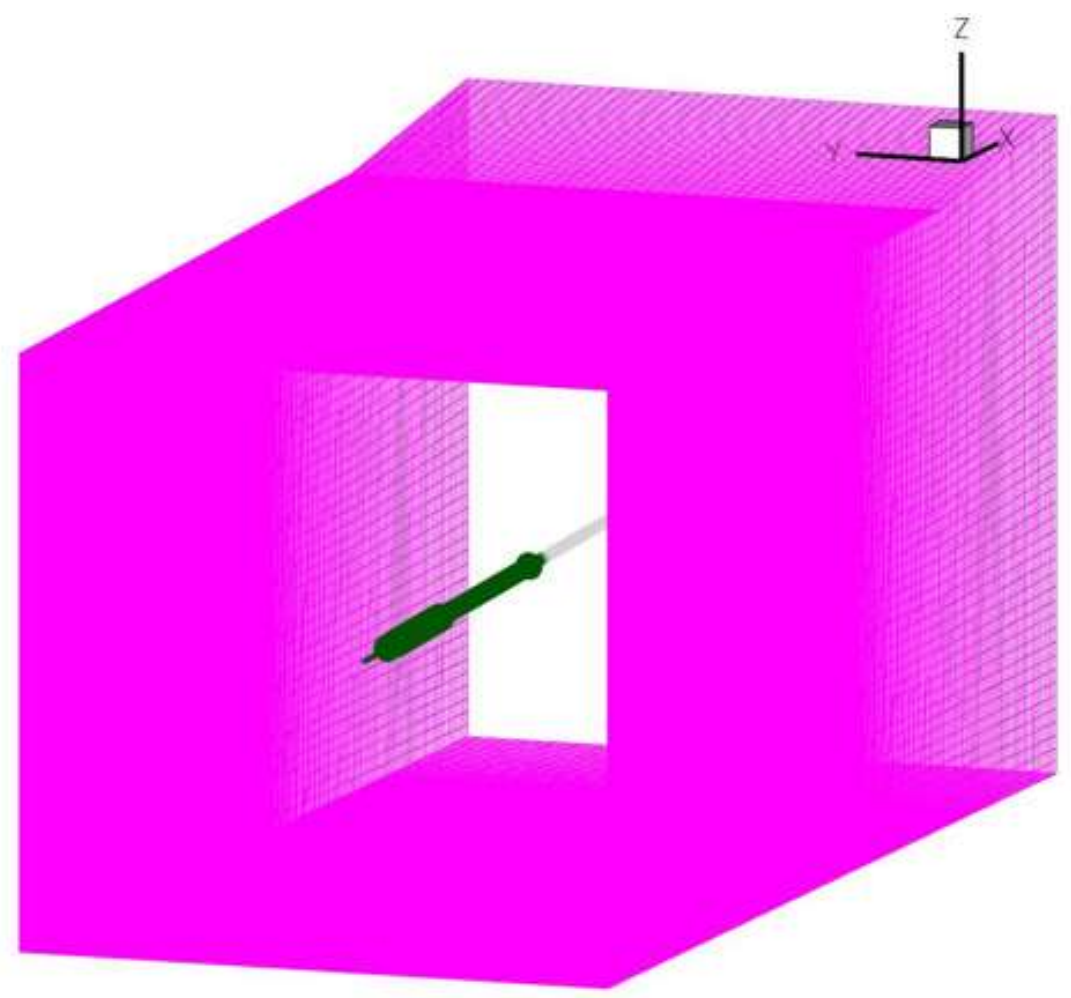

Figure 2: Tunnel Test Section \& Rocket Configuration 


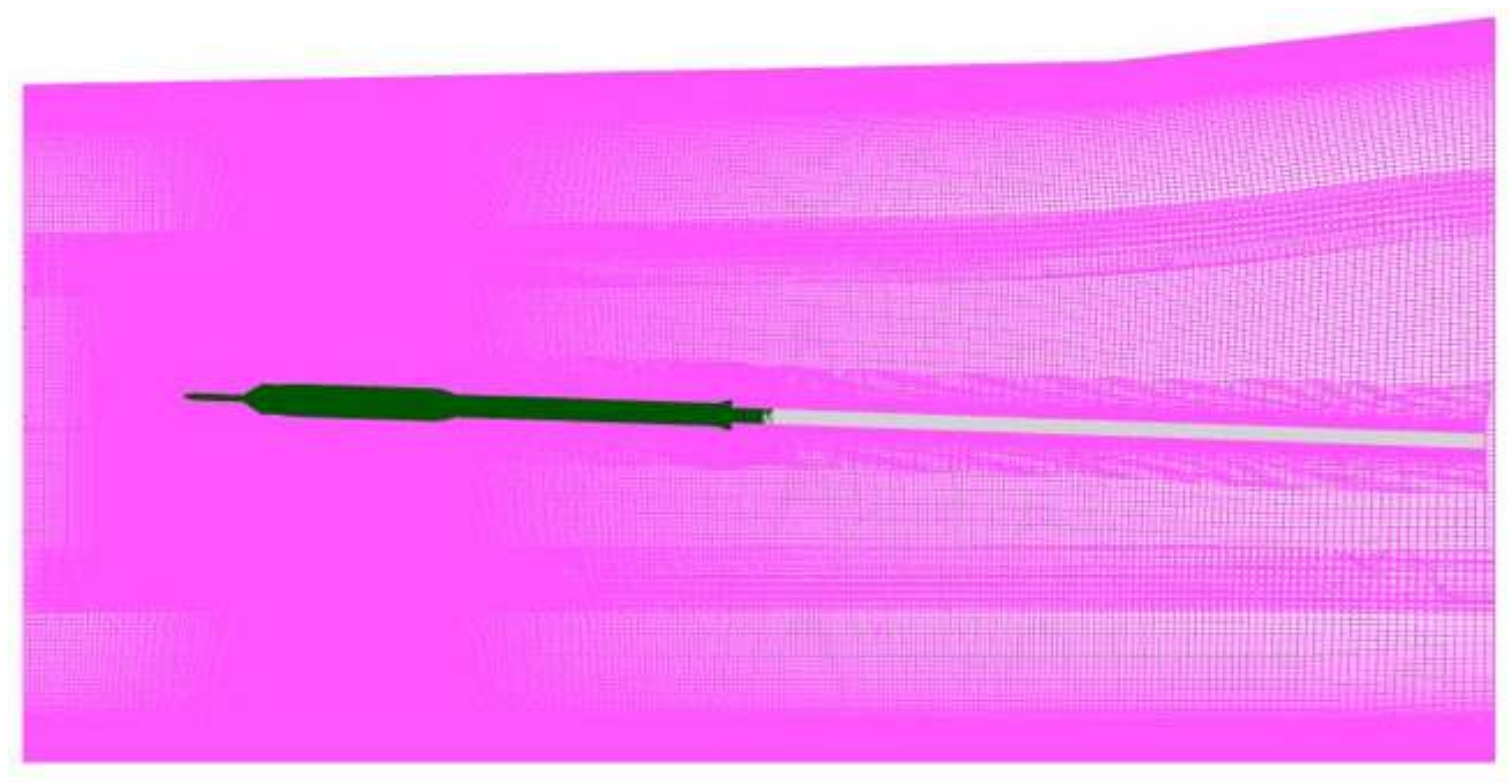

Figure 3: Tunnel Test Section \& Test Article Symmetry Plane View

Table 1: Number of Grid Points Per Zone

\begin{tabular}{rr}
\hline \hline & \\
Zone & $\sharp$ Points \\
\hline Cap & 80053 \\
Tower & 830428 \\
Body & 6113637 \\
Skirt & 2140506 \\
Wall & 9090000 \\
Core & 1440000 \\
\hline Total & 20764877 \\
\hline \hline
\end{tabular}

\section{OVERFLOW Simulation}

OVERFLOW 2.0aa is used for the CFD simulations. ${ }^{2,3}$ The Spalart-Allmaras turbulence model is used to simulate the turbulence. ${ }^{4}$ The distance function used in the turbulence model is modified to exclude the minimum wall distance, because it causes an error in the calculation of the eddy viscosity, causing the boundary layer to grow too fast resulting in an oblique shock forming off the inlet walls. Full multi-grid cycles are used to accelerate the initial system convergence, and additional iterations are performed afterward to further converge the solution.

\section{Calculating Flow Angularity Effects}

The flow angularities caused by the growing boundary layer and the changing area of the tunnel entry section will produce an effective change in the AOA for the overall flow field. To calculate this effective flow angularity, or $\alpha_{u p}$, a procedure similar to the wind tunnel data reduction reported in Reference 5, is used. Runs are performed at $\pm 2^{\circ}$, and the coefficients of normal force are compared. Using the AOA and $C_{N}$ from the two runs, a line is fitted to these points and $\alpha_{u p}$ (i.e. where $C_{N}=0$ ) is calculated. Equation 1 shows 
how $\alpha_{u p}$ is calculated, and Table 2 shows the results of the $\pm 2^{\circ}$ simulation and the calculated $\alpha_{u p}$. Mach and flow angularity contour plots of the runs performed and their corresponding residuals can be found in Appendix A. Note that a negative $\alpha_{u p}$ indicates a positive AOA for the flow angularity.

$$
\alpha_{u p}=\alpha_{2^{\circ}}-C_{N_{2} \circ}\left(\alpha_{2^{\circ}}-\alpha_{-2} \circ\right) /\left(C_{N_{2} \circ}-C_{N_{-2} \circ}\right)
$$

Table 2: Calculating Flow Angularity Correction

\begin{tabular}{rr}
\hline \hline AOA & $C_{N}$ \\
\hline 2 & 0.2698 \\
-2 & -0.2069 \\
\hline$\alpha_{u p}$ & -0.2639 \\
\hline \hline
\end{tabular}

\section{Calculating the Correction for the Pitch Moment}

Due to model and flow field asymmetries the pitch moment is not necessarily zero when $C_{N}=0$. The $C_{N}$ and $C_{A}$ are corrected by the angle of attack adjustment with the flow angularity. The same flow angularity will not always correct the pitch moment. Therefore the pitch moment is corrected by shifting the entire $C_{m y}-\alpha$ curve by $\Delta C_{m y}$ such that $C_{m y}=0$ at $\alpha=\alpha_{u p}$. The shift is determined by

$$
\Delta C_{m y, a_{u p}}=C_{m y, 2^{\circ}}-\left(C_{m y, 2^{\circ}}-C_{m y,-2^{\circ}}\right)\left(\alpha_{u p}-\alpha_{-2^{\circ}}\right) /\left(\alpha_{2^{\circ}}-\alpha_{-2^{\circ}}\right)
$$

The definitions of the flow angularity and the $C_{m y}$ shift are shown graphically in Figure 4 . Again note that a negative value for $\alpha_{u p}$ indicates a positive AOA for the flow angularity. 

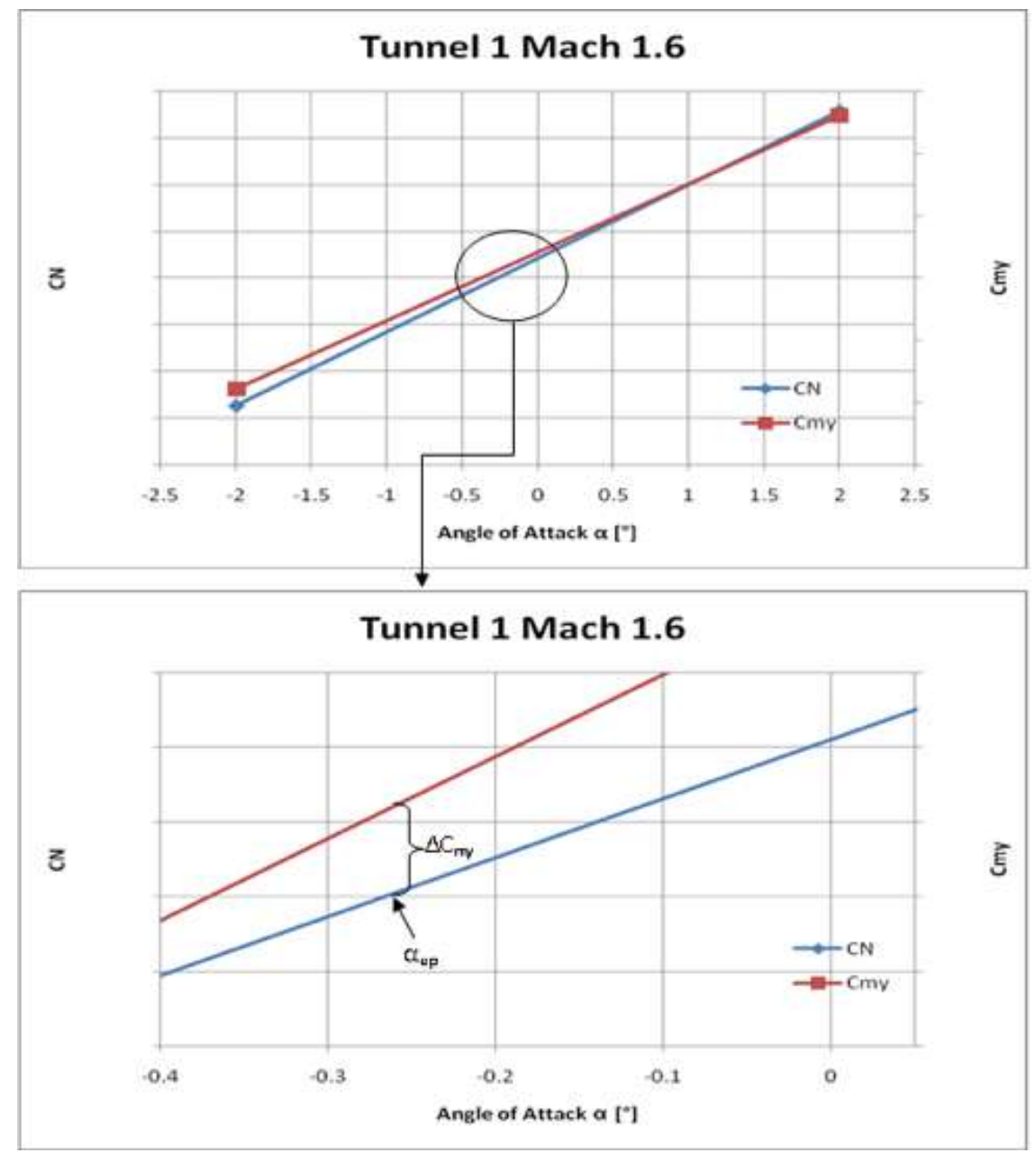

Figure 4: Correction Factors for Flow Angularity and $\Delta C_{m y}$ Shift

\section{Correcting for the discrepancies between the inlet Mach number and Pressure and the nominal values}

Since the Mach numbers and pressures at the entrance of the test section are not quite equal to the nominal values, the force and moment coefficients have been rescaled. The same procedure used in Reference 1 to obtain the calibrated Mach number and pressure are followed. To determine the calibrated Mach number and pressure, the values at select locations in the x-z plane of the test section are averaged. Five longitudinal (x-dir) survey stations are used between 0 in and 48 in, and four vertical (z-dir) survey stations are used at $\pm 10.8 \mathrm{in}$ and at $\pm 3.6 \mathrm{in}$. For the vertical direction, the two probes closest to the center-line are given full weight, while the outer two data points given half weights. For test section 1, the first and last longitudinal points are given half weights and the rest given full weights. For test section 2, all longitudinal points are weighted equally.

Because of the difference between the nominal values (free stream) and the calibrated values, the F\&M results have to be rescaled by $\left(P_{\text {nom }} / P_{\text {inlet }}\right) *\left(M_{\text {nom }} / M_{\text {inlet }}\right)^{2}$. For example, for test section 1 at nominal Mach number of 1.6, the calibrated Mach number is 1.588. The corresponding nominal and inlet pressures are $1 / 1.4$ and 0.71921 , respectively. 


\section{Evaluating the correction for the effective flow angularity}

To evaluate how well the calculated $\alpha_{\text {up }}$ predicts the effective flow angularity, runs at the corrected angles for $\pm 7^{\circ}$ are performed, and the normal forces are analyzed. The corrected $\pm 7^{\circ} \mathrm{AOA}$ is defined as $\pm 7^{\circ}+$ $\alpha_{\text {up }}$. The same initial conditions applied to the $\pm 2^{\circ}$ runs are used. Additionally, these runs are compared to a free air run at $+7^{\circ}$. Contour plots of the Mach numbers and flow angularities and their corresponding residuals can be found in Appendix A.

\section{Calculating Boundary Layer}

The boundary layer thickness, displacement thickness, and momentum thickness of the tunnel simulations are also calculated. The boundary-layer thickness is defined as the distance from the wall to the point where $u(y)=0.99 u_{o}$, where $u_{o}$ is taken to be the streamwise component of velocity measured at the centerline of the entrance to the test section (at $0,0,0)$. The compressible definition for displacement and momentum thickness is used. Displacement thickness is taken to be

$$
\delta^{*}=\int_{o}^{\infty}\left(1-\frac{\rho u(y)}{\rho_{o} u_{o}}\right) d y
$$

and momentum thickness is taken to be

$$
\theta=\int_{o}^{\infty} \frac{\rho u}{\rho_{o} u_{o}}\left(1-\frac{u(y)}{u_{o}}\right) d y
$$

where $\rho_{o}$ and $u_{o}$ are the values at the centerline of the entrance to the test section (at $\left.0,0,0\right)$. Both equations are integrated numerically using the trapezoidal rule.

\section{Results of Simulating Complete UPWT}

The difference in the results shows that the correction applied does not account for all of the flow angularities or Mach non-uniformity effects. It is very likely that interactions between the tunnel walls and test section inflow conditions and model are not adequately compensated for by the correction. Because the model is quite large in comparison to the tunnel test section cross-sectional area, tunnel-model interactions are more likely to occur.

Figure 5 shows the complete tunnel geometry for test section 1. Figure 6 shows the grid system and Figure 7 shows the numerical solution of the empty tunnel in terms of Mach contours. Figures 8 and 9 show the Mach contours in the symmetry plane of the test section obtained from the numerical simulations and the experimental data. Unfortunately the experimental data are not taken at exactly the desired inlet Mach number. The closest Mach number to the simulation Mach number of 1.6 obtainable from the calibration report is Mach 1.469. Figures 10 and 11 show the corresponding flow angularities from the simulations and experiment.

Similar simulations are performed at Mach $=2.5$ for the low speed test section and at Mach 2.5 and 4.0 for test section 2. Figure 12 shows the complete tunnel geometry for test section 2, and figure 13 shows the grid system. A similar sequence of results as shown above are presented in Figures 14 through 18 for the Mach 4 case.

The boundary layer thicknesses at the entrance of the test section are also in good agreement with the tunnel data (Figure 19). The trends of the data are similar to the tunnel data, while the overall shift in the data could be a result of the simulation model. A thinner boundary layer is expected, because only the inlet through the test section are included in this simulation.

The same procedure as described above is followed to compute all 4 cases and the discrepancies between the computed tunnel results at the corrected angles of attack and pitch moment shifts and the free air (no tunnel) simulations are determined. These results are shown in Figure 20 and 21. Note: Figure 20's values for normal, axial, and pitch coefficient are rescaled by arbitrary numbers to make it ITAR free.

With the more representative entry section the inlet flow conditions of the test section obtained from the simulations are in much better agreement with the reported results of the calibration report. ${ }^{1}$ While the

Mach contours and the flow angularities are not in perfect agreement with the calibration report, they are 
representative and should provide a good first order indication of the errors in the reported wind tunnel data due to flow non-uniformities (Mach and flow angularities).

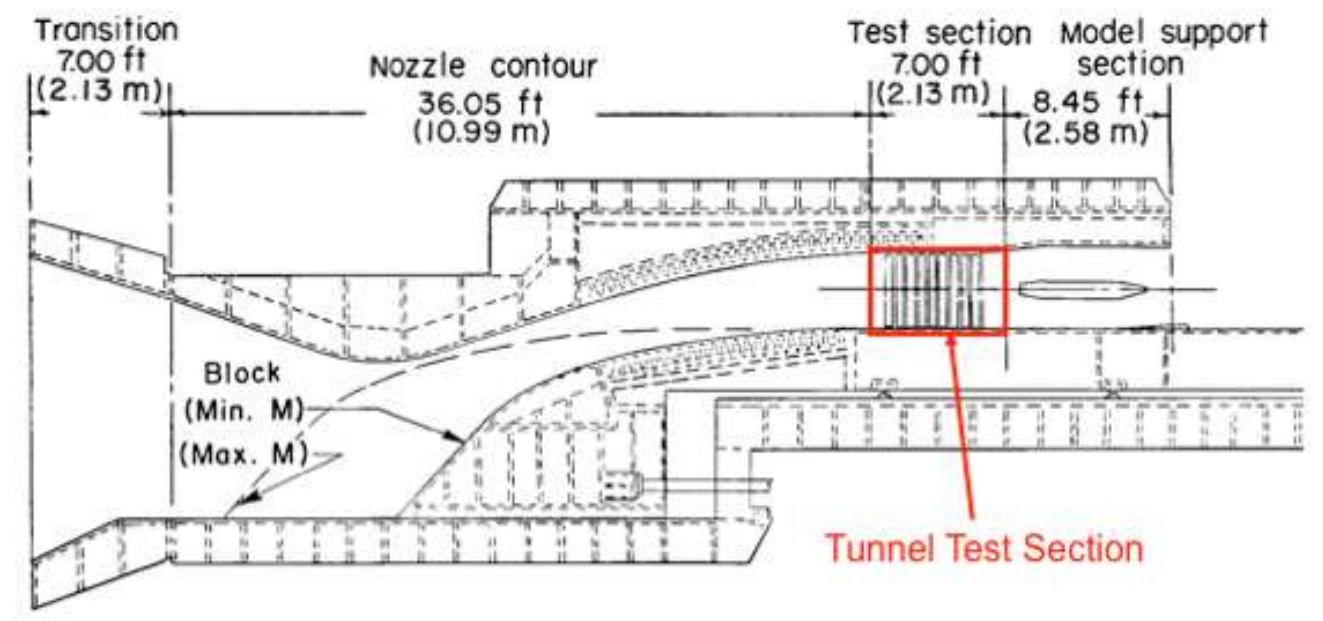

Figure 5: UPWT Entry and Test Section 1

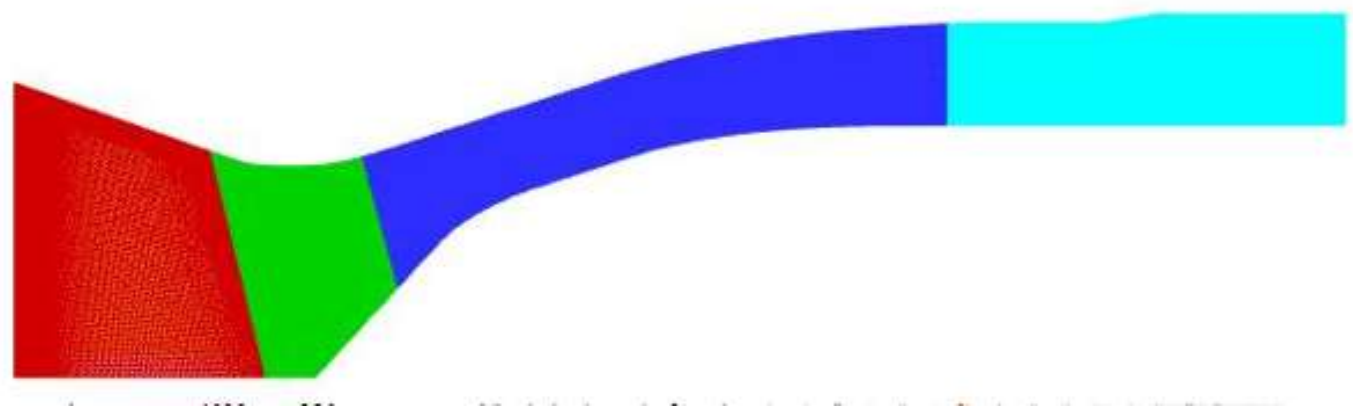

Figure 6: Grid System for Entire UPWT with Test Section 1 at Mach 1.6

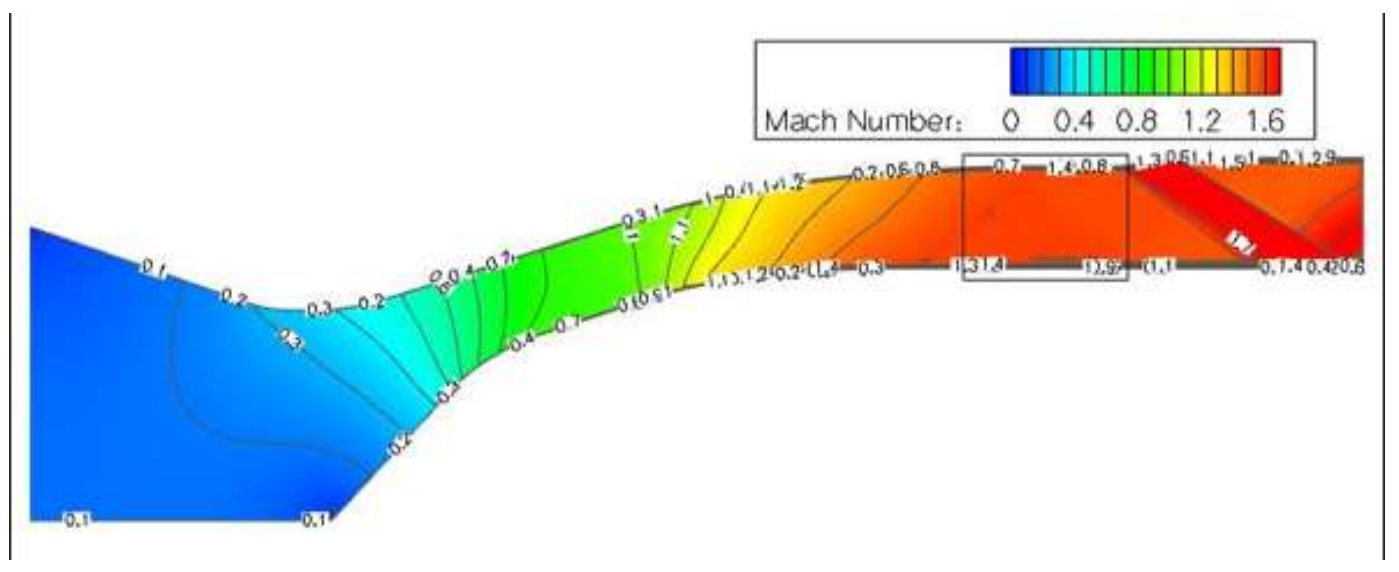

Figure 7: Computed Mach Contours of Entire UPWT with Test Section 1 at Mach 1.6 


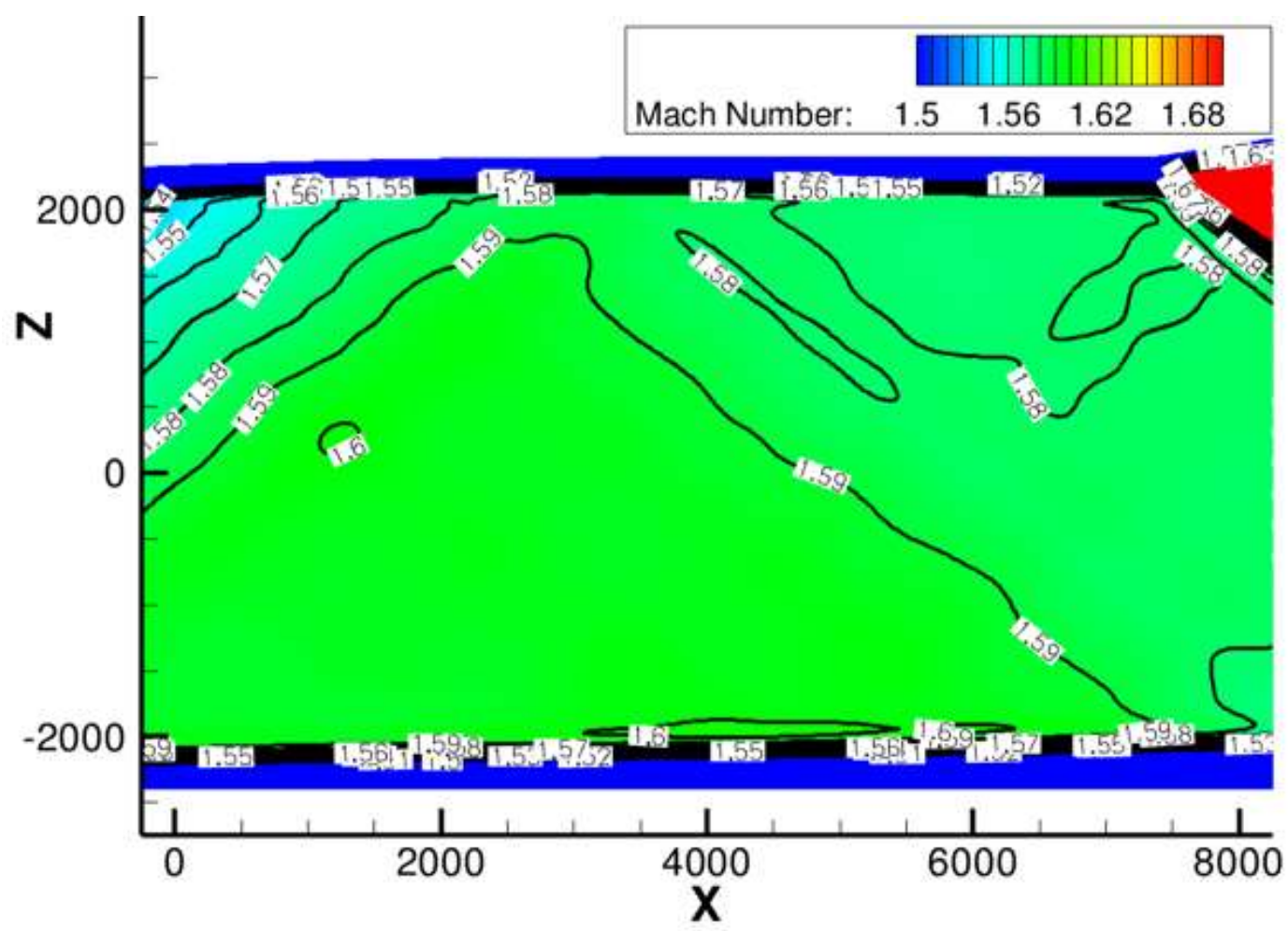

Figure 8: Computed Mach Contours of UPWT Test Section 1 at Mach 1.6

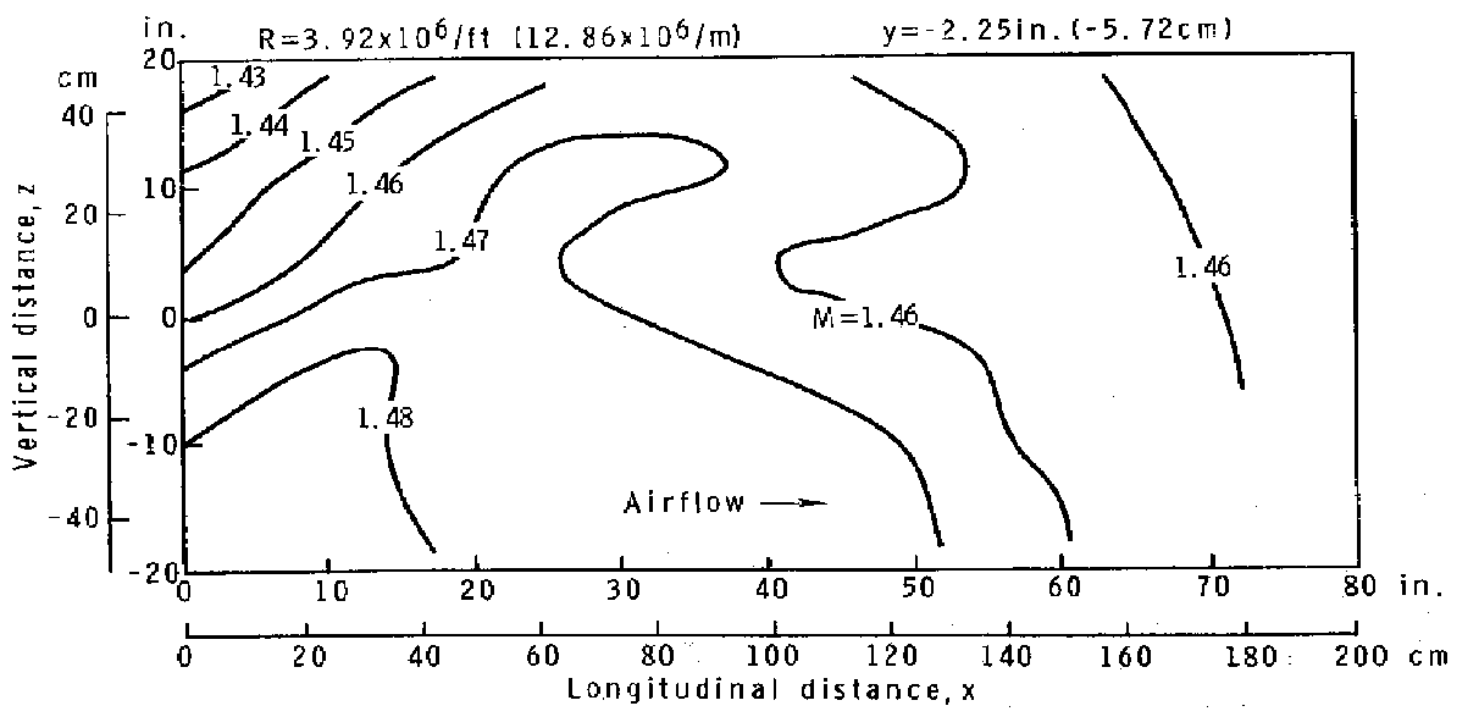

Figure 9: Experimental Mach Contours of UPWT Test Section 1 at Mach 1.469 


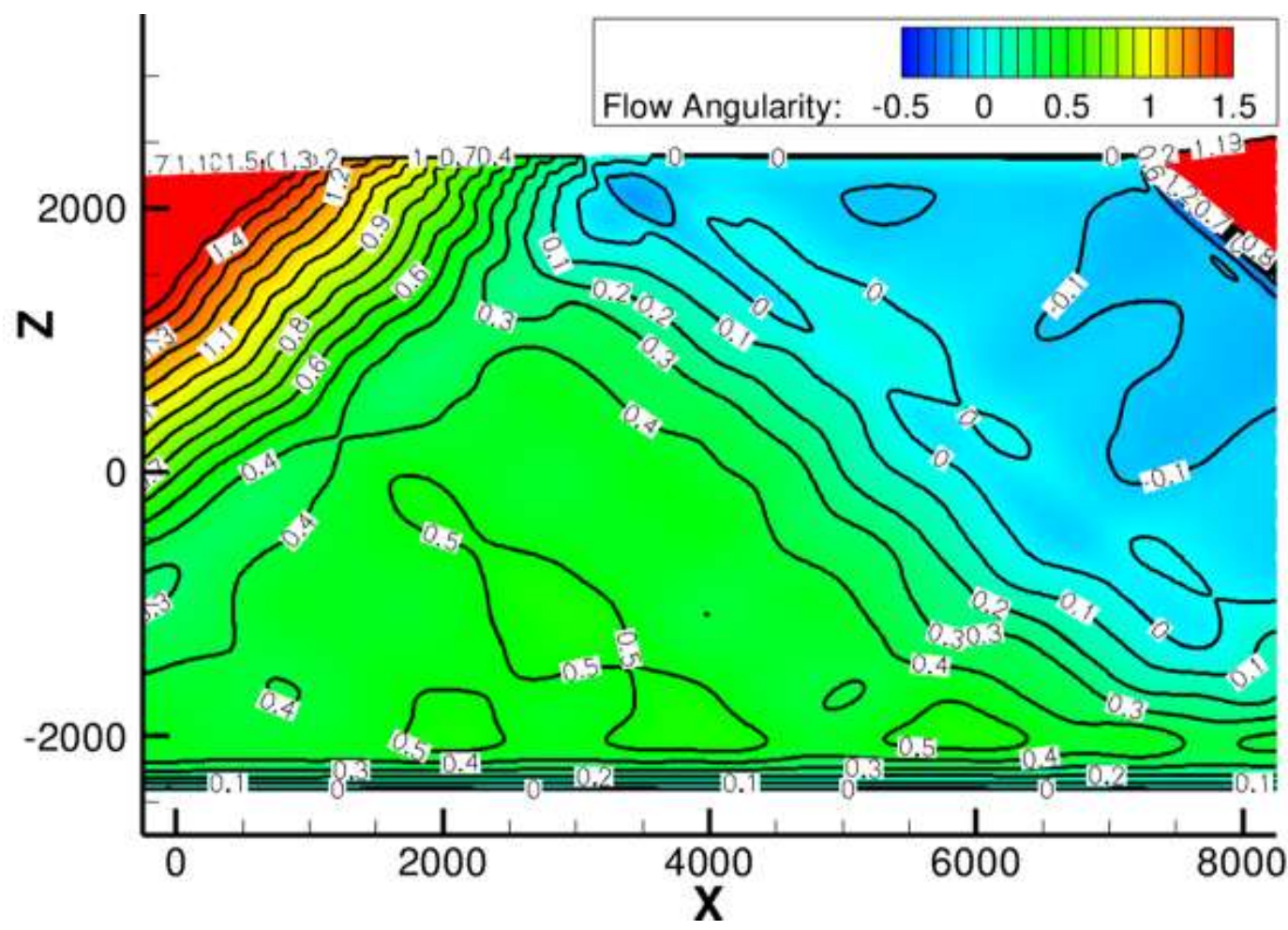

Figure 10: Computed Flow Angularity of UPWT Test Section 1 at Mach 1.6

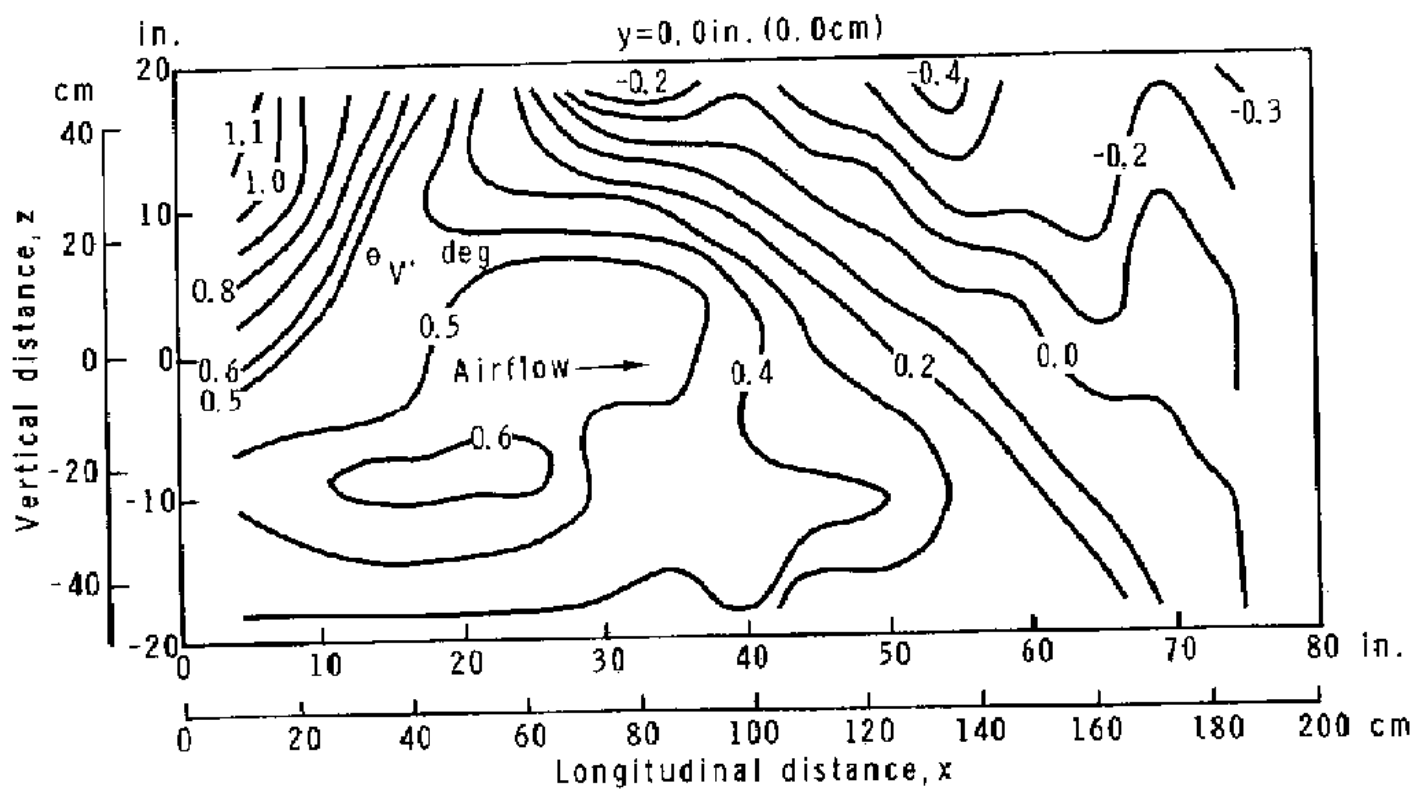

Figure 11: Experimental Flow Angularity of UPWT Test Section 1 at Mach 1.57 


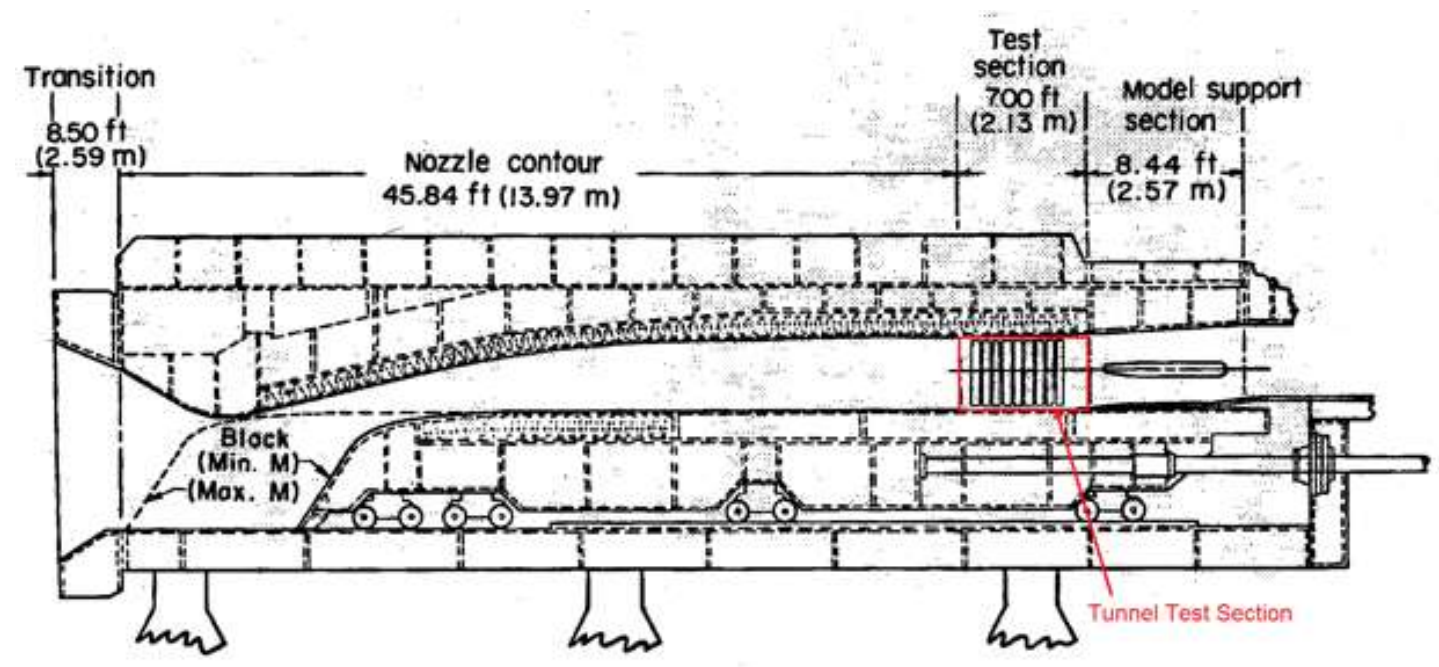

Figure 12: UPWT Entry and Test Section 2

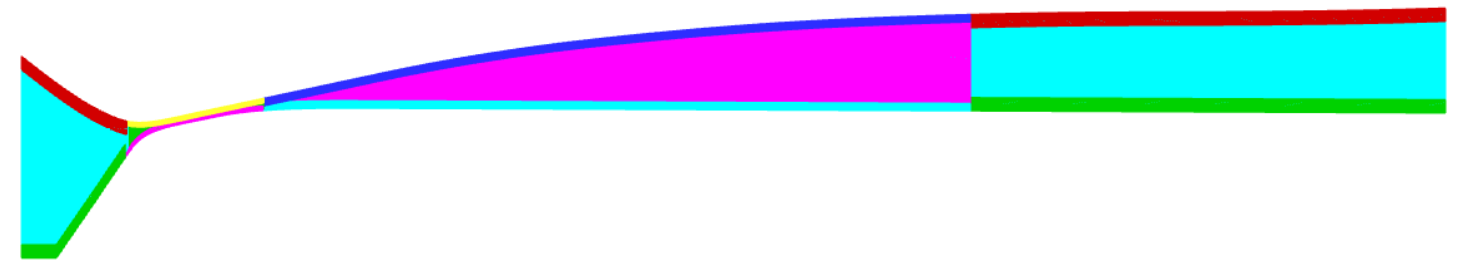

Figure 13: Grid System for Entire UPWT with Test Section 2 at Mach 4.0

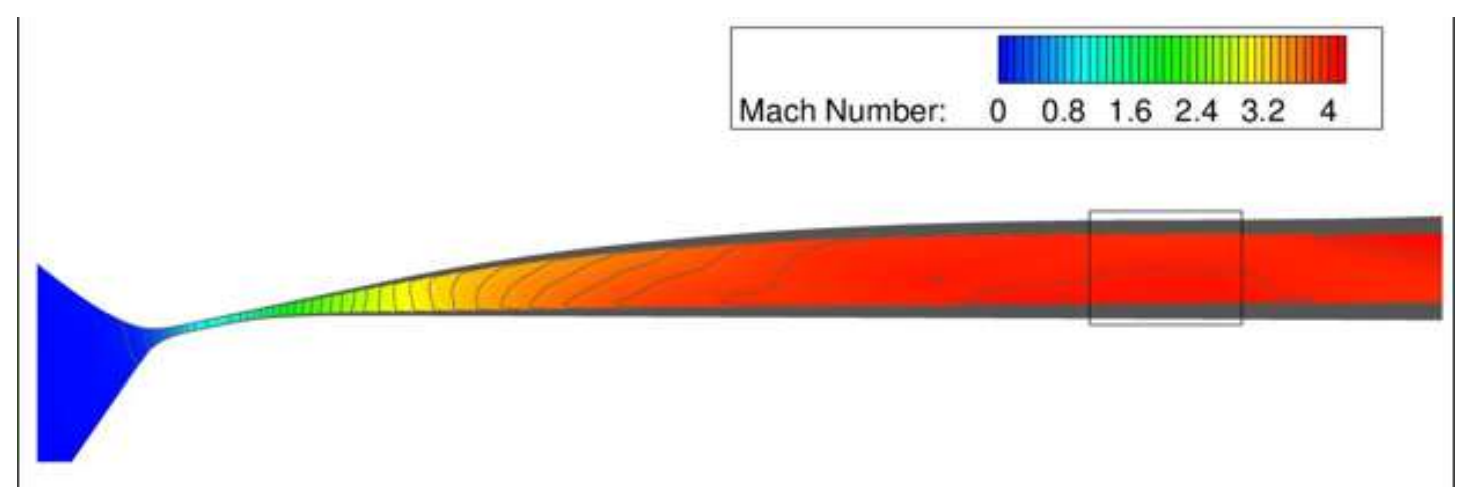

Figure 14: Computed Mach Contours of Entire UPWT with Test Section 2 at Mach 4.0 


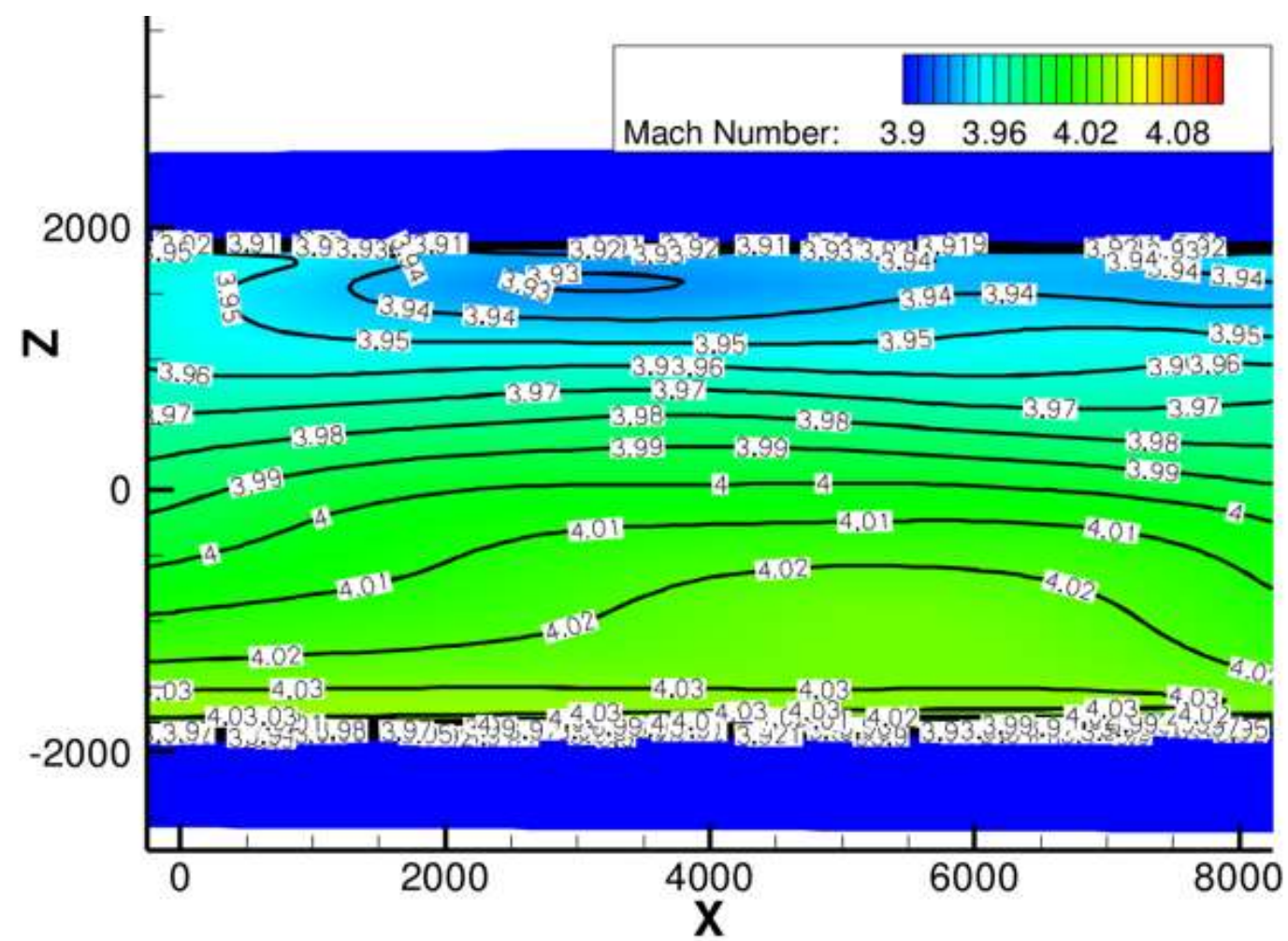

Figure 15: Computed Mach Contours of UPWT Test Section 2 at Mach 4.0

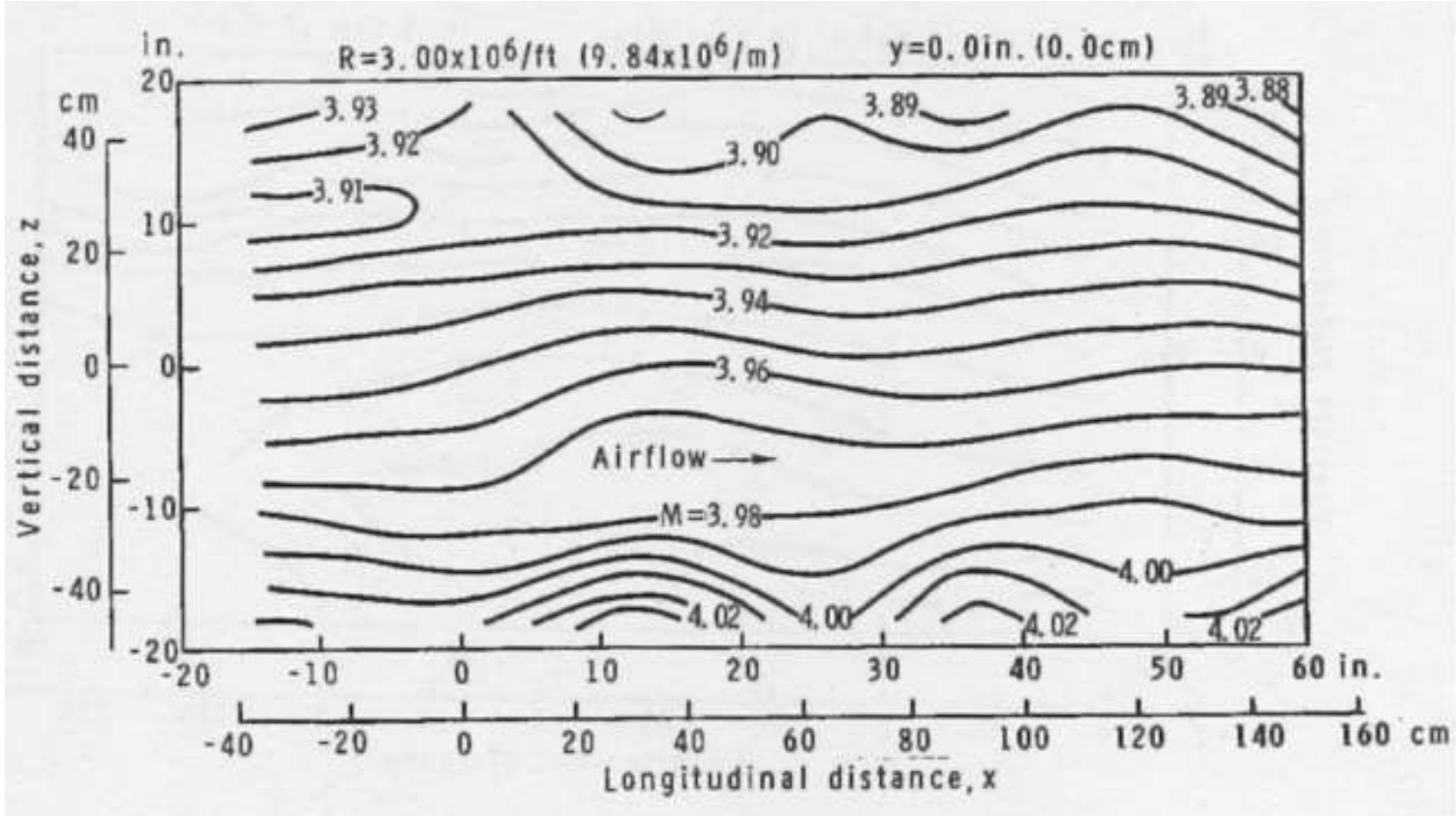

Figure 16: Experimental Mach Contours of UPWT Test Section 2 at Mach 3.953 


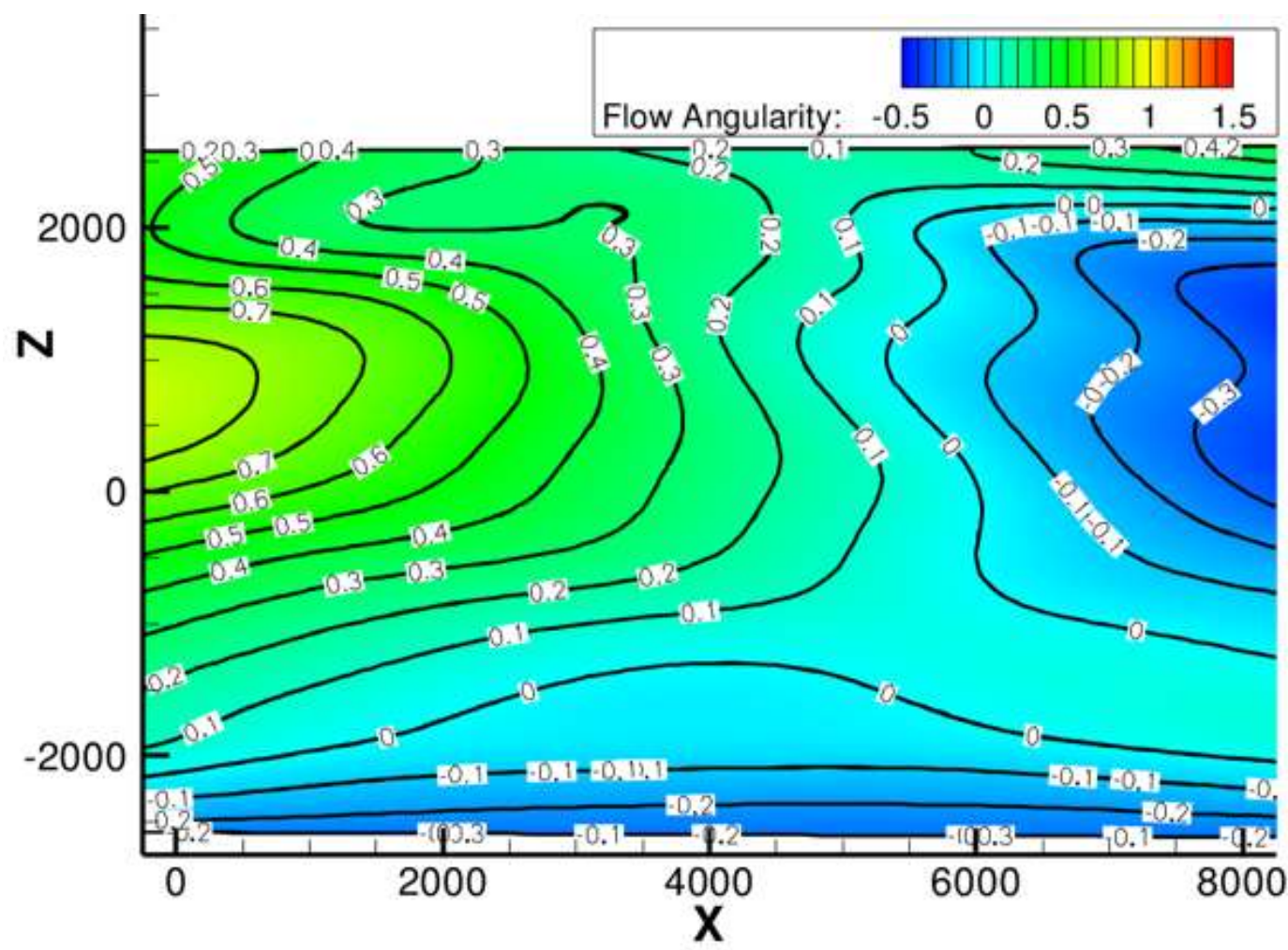

Figure 17: Computed Flow Angularity of UPWT Test Section 2 at Mach 4.0

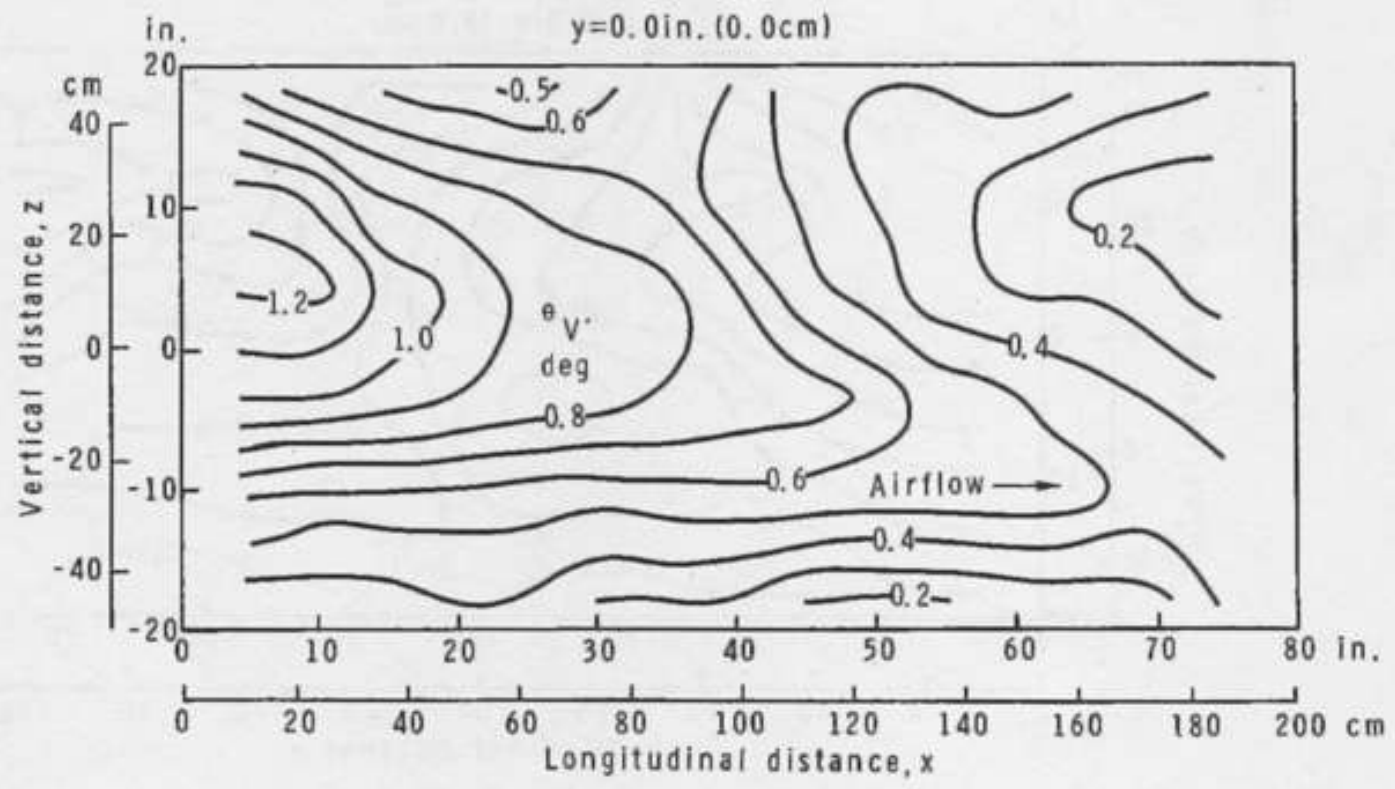

Figure 18: Experimental Flow Angularity of UPWT Test Section 2 at Mach 4.185 


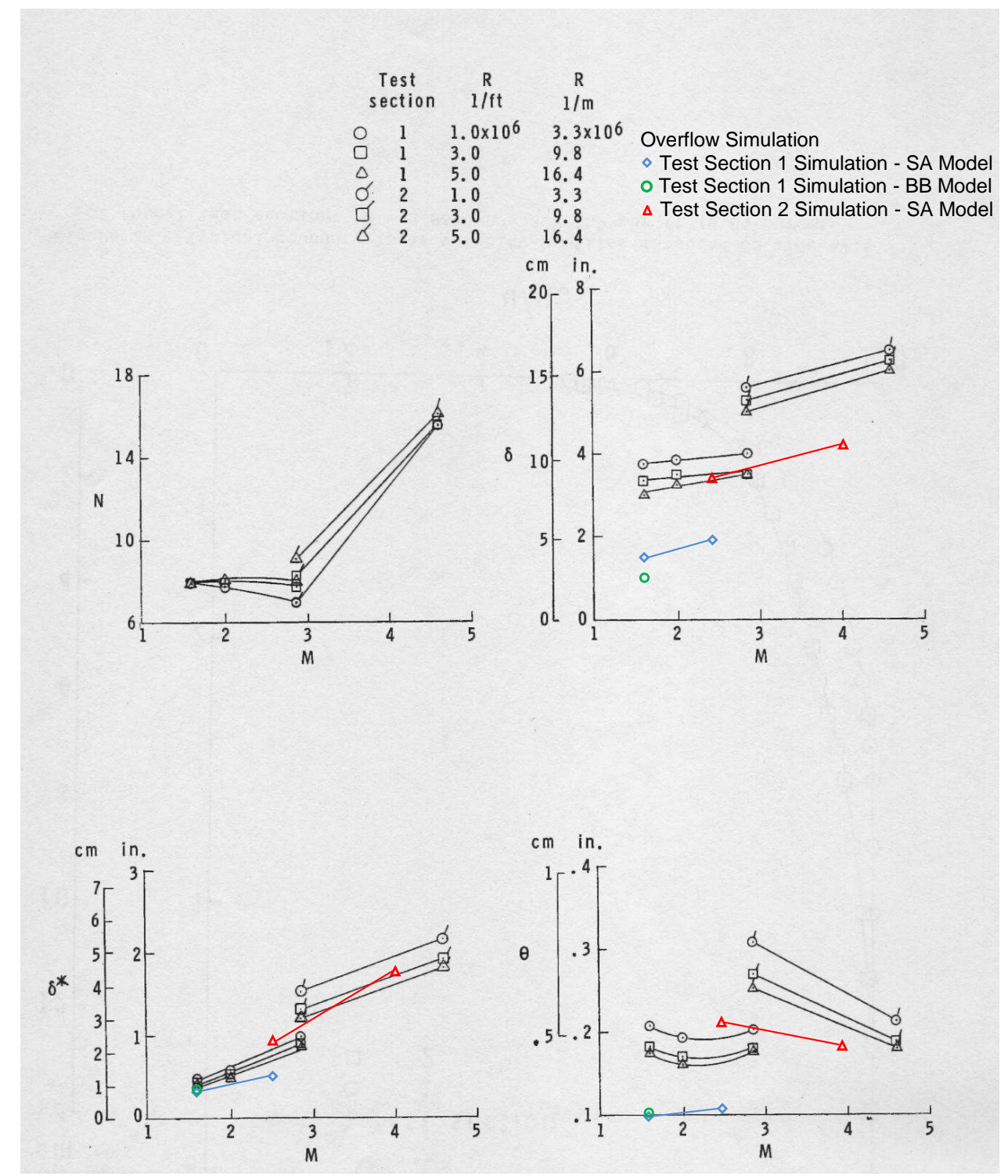

Figure 19: Boundary Layer Properties of UPWT and Overflow Computational Results 


\begin{tabular}{|c|c|c|c|c|c|c|c|c|}
\hline & $\operatorname{Nom} \alpha$ & Corr $\alpha$ & Mach & $\mathrm{C}_{\mathrm{N}}$ & $\mathrm{C}_{\mathrm{A}}$ & Corr-Pitch (Y) & Effective $\boldsymbol{\alpha}_{\mathrm{up}}$ & $\Delta \mathrm{Cmy}$ \\
\hline \multicolumn{9}{|l|}{ Tunnel 1} \\
\hline M1.6 & & & & & & & \multirow[t]{6}{*}{-0.2683} & \multirow[t]{6}{*}{0.3998} \\
\hline tunnel & 2 & 2.0000 & 1.6 & 0.2720 & 1.8096 & 9.0368 & & \\
\hline tunnel & -2 & -2.0000 & 1.6 & -0.2077 & 1.7857 & -6.2006 & & \\
\hline tunnel & 7 & 6.7317 & 1.6 & 0.7224 & 1.9797 & 26.1202 & & \\
\hline tunnel & -7 & -7.2683 & 1.6 & -0.6986 & 1.9755 & -25.4942 & & \\
\hline no tunnel (nt) & 7 & 7.0000 & 1.6 & 0.7114 & 1.9795 & 25.8937 & & \\
\hline$\%$ error 7 to -7 & & & 1.6 & 3.3379 & 0.2098 & 2.4176 & & \\
\hline$\%$ error 7 to nt & & & 1.6 & 1.5353 & 0.0100 & 0.8747 & & \\
\hline \multirow[t]{2}{*}{$\%$ error -7 to $n t$} & & & 1.6 & -1.8026 & -0.1998 & -1.5429 & & \\
\hline & & & & & & & & \\
\hline M2.5 & & & & & & \multirow{6}{*}{$\begin{array}{r}10.6404 \\
-5.7440 \\
30.2508 \\
-30.0397 \\
30.2571\end{array}$} & \multirow[t]{6}{*}{-0.9605} & \multirow[t]{6}{*}{-1.4920} \\
\hline tunnel & 2 & 2.0000 & 2.5 & 0.2969 & 1.5500 & & & \\
\hline tunnel & -2 & -2.0000 & 2.5 & -0.1043 & 1.5486 & & & \\
\hline tunnel & 7 & 6.0395 & 2.5 & 0.7802 & 1.5994 & & & \\
\hline tunnel & -7 & -7.9605 & 2.5 & -0.8350 & 1.6183 & & & \\
\hline no tunnel (nt) & 7 & 7.0000 & 2.5 & 0.8114 & 1.6134 & & & \\
\hline$\%$ error 7 to -7 & & & 2.5 & -6.7548 & -1.1682 & 0.6979 & & \\
\hline$\%$ error 7 to nt & & & 2.5 & -3.8434 & -0.8648 & -0.0206 & & \\
\hline$\%$ error -7 to nt & & & 2.5 & 2.9114 & 0.3033 & -0.7185 & & \\
\hline \multicolumn{9}{|l|}{ Tunnel 2} \\
\hline $\mathrm{M} 2.5$ & & & & & & & \multirow[t]{6}{*}{-0.0110} & \multirow[t]{6}{*}{-0.2058} \\
\hline tunnel & 2 & 2.0000 & 2.5 & 0.1963 & 1.5555 & 8.3964 & & \\
\hline tunnel & -2 & -2.0000 & 2.5 & -0.1941 & 1.5552 & -8.7286 & & \\
\hline tunnel & 7 & 6.9890 & 2.5 & 0.8286 & 1.6232 & 31.1568 & & \\
\hline tunnel & -7 & -7.0110 & 2.5 & -0.8094 & 1.6127 & -30.4207 & & \\
\hline no tunnel (nt) & 7 & 7.0000 & 2.5 & 0.8114 & 1.6134 & 30.2571 & & \\
\hline$\%$ error 7 to -7 & & & 2.5 & 2.3610 & 0.6545 & 2.4329 & & \\
\hline$\%$ error 7 to nt & & & 2.5 & 2.1203 & 0.6113 & 2.9737 & & \\
\hline$\%$ error -7 to nt & & & 2.5 & -0.2407 & -0.0433 & 0.5407 & & \\
\hline & & & & & & & & \\
\hline M4.0 & & & & & & & -0.2672 & 0.1701 \\
\hline tunnel & 2 & 2.0000 & 4.0 & 0.2325 & 1.2425 & 9.5629 & & \\
\hline tunnel & -2 & -2.0000 & 4.0 & -0.1777 & 1.2362 & -7.0024 & & \\
\hline tunnel & 7 & 6.7328 & 4.0 & 0.9711 & 1.3185 & 35.2244 & & \\
\hline tunnel & -7 & -7.2672 & 4.0 & -0.9429 & 1.2837 & -33.2878 & & \\
\hline no tunnel (nt) & 7 & 7.0000 & 4.0 & & & & & \\
\hline$\%$ error 7 to -7 & & & 4.0 & 3.0187 & 2.6300 & 5.7433 & & \\
\hline$\%$ error 7 to nt & & & 4.0 & 4.0230 & -0.3578 & 4.4629 & & \\
\hline$\%$ error -7 to $n t$ & & & 4.0 & 1.0043 & -2.9878 & -1.2804 & & \\
\hline
\end{tabular}

Figure 20: Wind Tunnel Non-uniformity Induced Errors in the Longitudinal F and M Coefficients for DAC1 in the UPWT Test Sections 1 and 2 


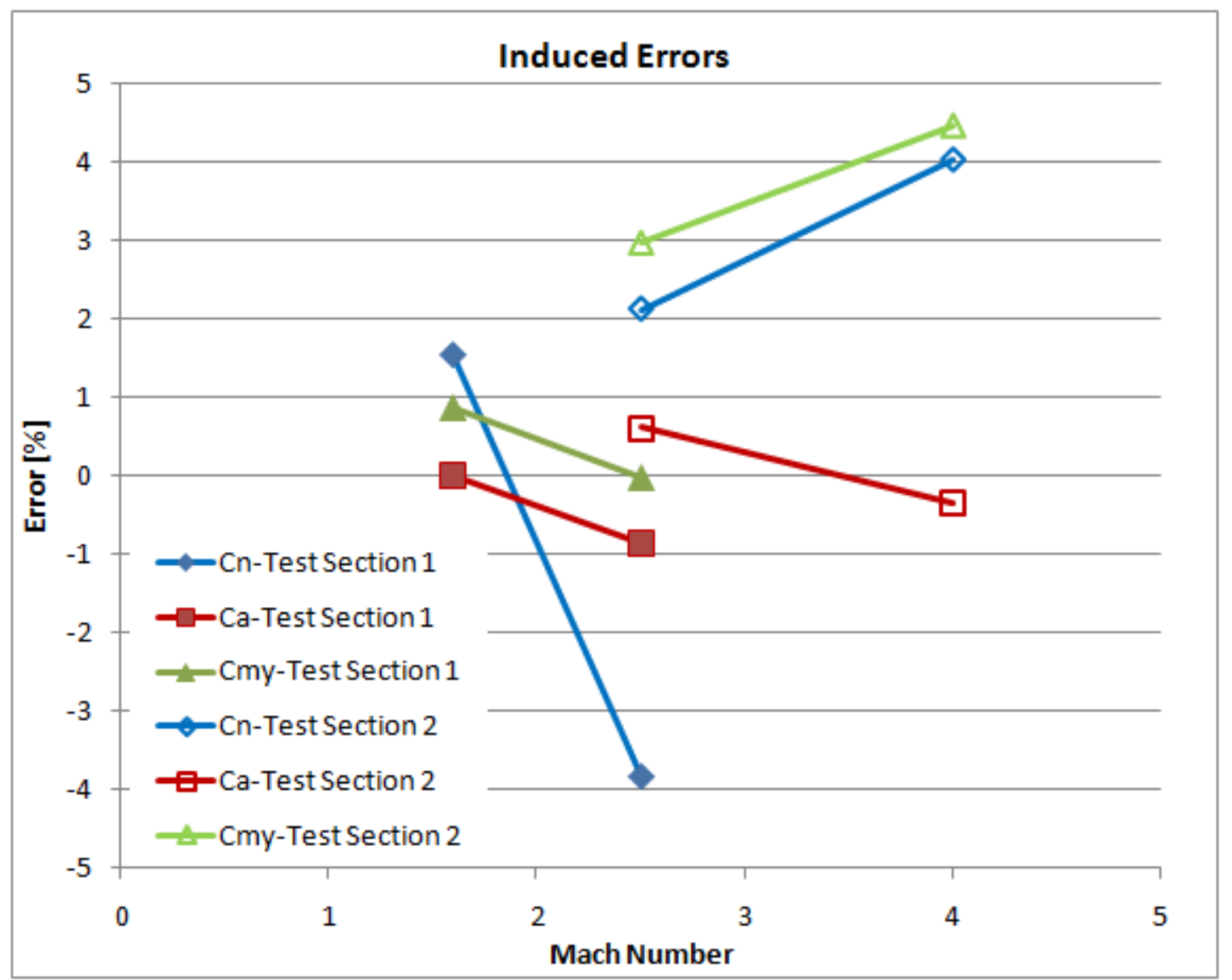

Figure 21: Wind Tunnel Non-uniformity Induced Errors in the Longitudinal F and M Coefficients for DAC1 in the UPWT Test Sections 1 and 2

As shown by Figure 20 and 21, the errors of $\mathrm{F} \& \mathrm{M}$ data are still substantial. The error is defined as $\left(C_{t u n}-C_{n t}\right) / C_{n t}$, where $\mathrm{C}$ is any one the force or moment coefficients. Figure 21 shows the percent error for the nominal $+7^{\circ}$ angle of attack. For $C_{N}$ the errors range from 1.5\% at Mach 1.6 to $4 \%$ at Mach 4 . The $C_{A}$ errors are $0.2 \%$ at Mach 1.6 to $\sim 0.4 \%$ at Mach 4 . The corresponding pitch moment errors range from $\sim 0 \%$ to $\sim 4.5 \%$ over the same Mach number range.

These errors can now be used to correct the reported wind tunnel data. ${ }^{5,6}$ The rationale behind this is quite simple. The same grid system around the DAC1 configuration, the same turbulence model, flow solver, boundary conditions, and convergence levels are used for all five cases. Therefore the effects of the CFD uncertainties are constant for all five cases and effectively vanish when increments are computed from these five cases. These increments (errors) can be used to correct the reported wind tunnel data without any fear of contamination from the CFD uncertainties. Any other effects in the CFD data will be due to the flow non-linearities occurring between $\alpha$ and $\alpha=\alpha_{\text {up }}$.

Following the guidelines of Reference 5, the corrected values are not used for the Mach 2.5 in Test Section 1. The reason for excluding this case is also evident from Figure 20. For this case the effective flow angularity is -0.960 . The magnitude of both is substantially larger than for the other 3 cases. Using only the three remaining cases the corrected values are shown in the following figures along with the original wind tunnel data and the prior CFD results reported at the 2nd CLV Aero TIM meeting. The corrections are only developed for Mach 1.6, 2.5, and 4.0 at $\alpha=+7^{\circ}$. The axial force, normal force, and pitch moment coefficients are shown in Figures 22, 23, and 24, respectively. The corrected wind tunnel data is in closer agreement with the CFD results. The errors in $C_{N}$ and $C_{m y}$ are now less than $2 \%$ at Mach 2.5 and 4 and less than $5 \%$ at Mach 1.6. The discrepancies between the CFD and the uncorrected wind tunnel are in excess of $5 \%$. The errors are still fairly large at Mach 1.6. This may be due to the larger tunnel wall interference 
effects at the lower Mach numbers. These wall effects are not likely to occur at the higher Mach numbers. It is also possible that the test section inlet flow angularities and flow non-uniformities are not resolved with enough precision. These discrepancies need further scrutiny.

\section{DAC1_5m-CEV_5.5m-US -- CA, Axial Force Coefficient}

Overflow $2.0 \mathrm{z}-1$ \% scale wind tunnel; Rey,d $=, 487 \mathrm{M}$

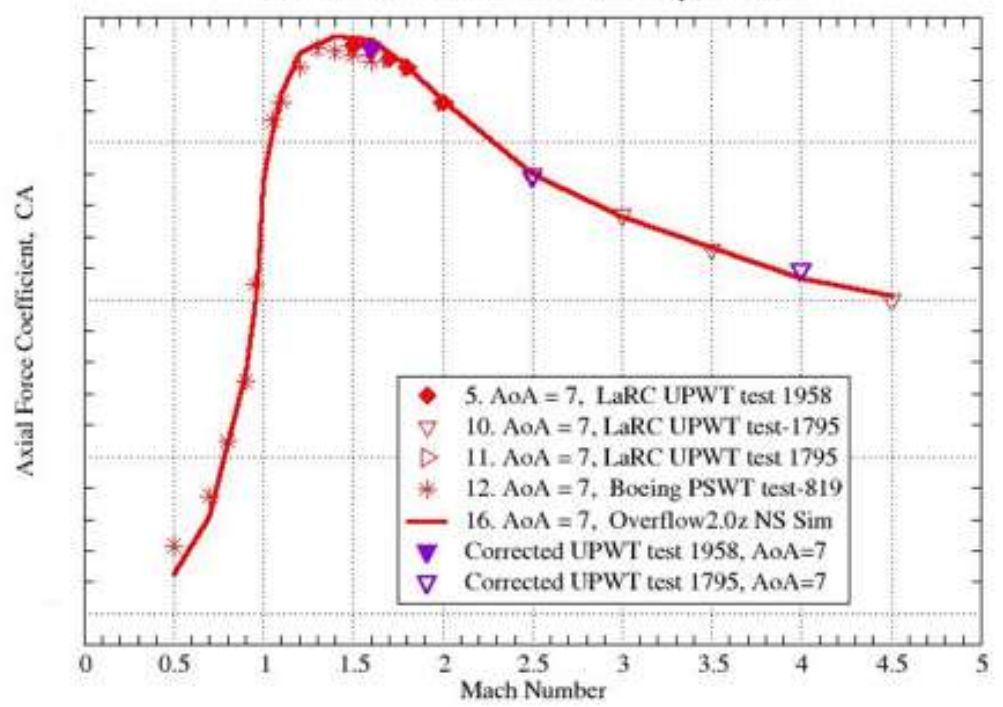

Figure 22: Comparison of the Axial Force Coefficients for DAC1 in the UPWT Test Sections 1 and 2 with the corrected UPWT data and the Overflow results

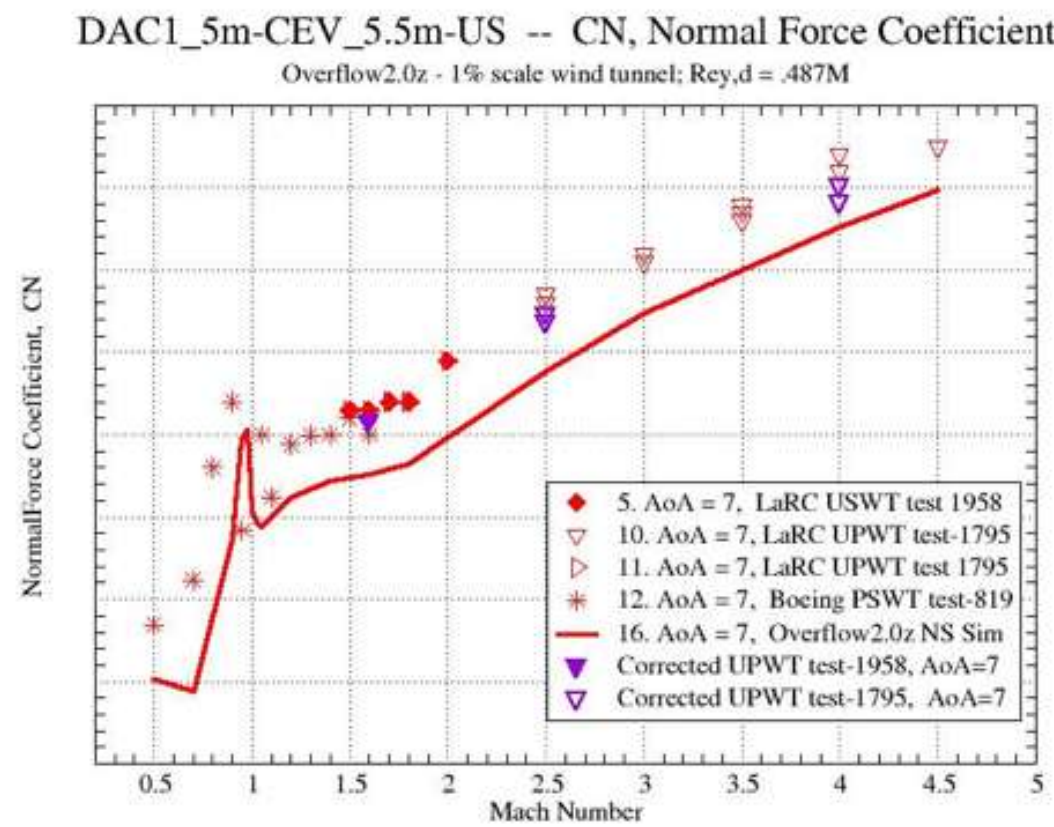

Figure 23: Comparison of the Normal Force Coefficients for DAC-1 in the UPWT Test Sections 1 and 2 with the corrected UPWT data and the Overflow results 


\section{DAC1_5m-CEV_5.5m-US -- Cm, Pitch Moment Coefficient}

Overflow $2.0 \mathrm{z}-1 \%$ scale wind tunnel: Rey, $\mathrm{d}=.487 \mathrm{M}$

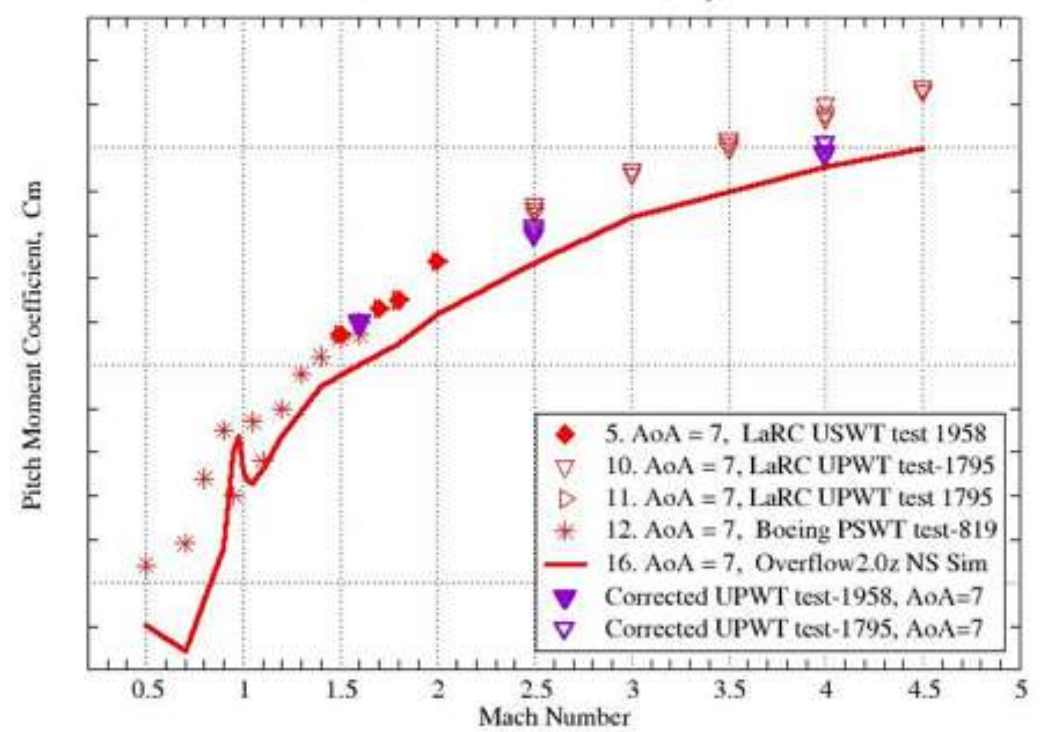

Figure 24: Comparison of the Pitch Moment Coefficients for DAC-1 in the UPWT Test Sections 1 and 2 with the corrected UPWT data and the Overflow results

\section{Grid Refinement}

To see if refining the grid would yield a different solution, simulations are run using an adjoint-based refined grid (from Cart3D). ${ }^{7}$ Figure 25 shows the Cart3D adjoint-based refined grid, as well as the corresponding domain of influence and the domain of dependence regions. The near body grids are refined using the same near-body spacing as the adjoint-based refined grid. Additionally, an off-body grid is added to increase the grid resolution encapsulated by the domain of influence and domain of dependence regions. The runs with the new adjoint grid are performed at Mach 1.6, and compared with the old grid system. Figure 26 shows the adjoint-based grid that is added. Table 3 outlines the number of grid points per zone. Figure 29 shows the induced errors for the adjoint grid, compared with the original grid. The difference in the induced errors between the two different grid systems is small, implying that the adjoint grid did little to change the solution. Note: Figure 29's values for normal, axial, and pitch coefficient are rescaled by arbitrary numbers to make it ITAR free.

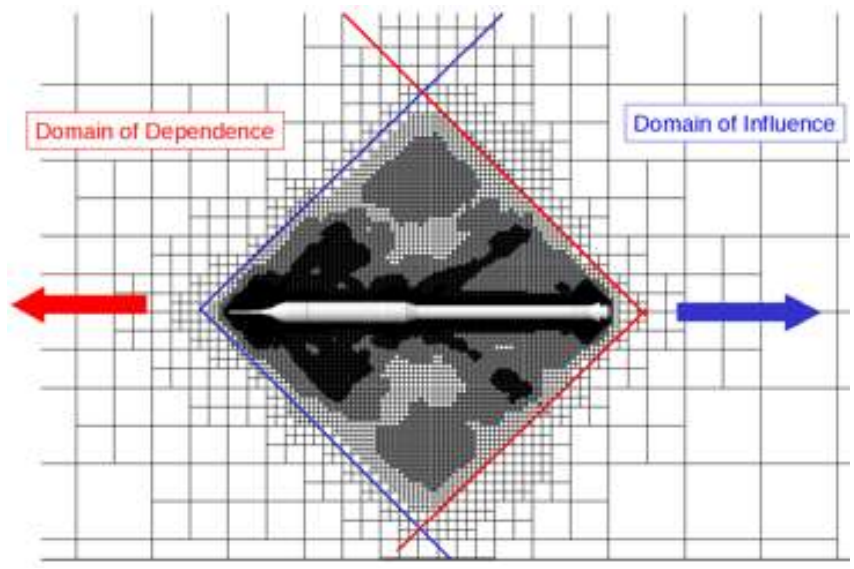

Figure 25: Adjoint-based grid from Cart3D 


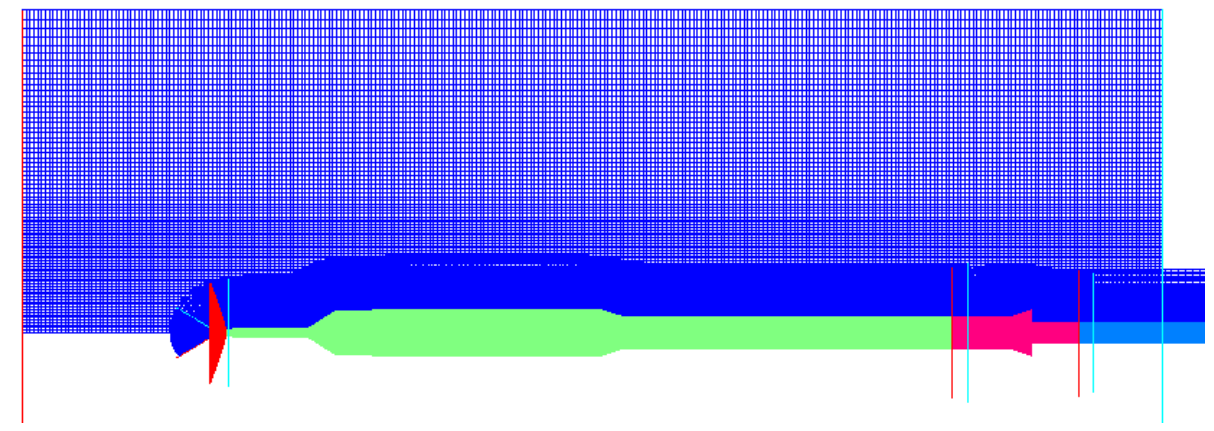

Figure 26: Grid for the adjoint-based body grids for the DAC-1 model

Table 3: Number of Grid Points Per Zone, Adjoint Grid

\begin{tabular}{rr}
\hline \hline Zone & $\sharp$ Points \\
\hline Cap & 80053 \\
Tower & 1447638 \\
Body & 6817908 \\
Skirt & 3408954 \\
Near-Body & 4538575 \\
Wall & 9090000 \\
Core & 1440000 \\
\hline Total & 46296194 \\
\hline \hline
\end{tabular}

\section{Comparison with Baldwin-Barth turbulence model}

To determine the effect of the turbulence model on the results of the simulations, runs are performed again at $M=1.6$ using the Baldwin-Barth turbulence model. ${ }^{8}$ Figures 27 and 28 show the Mach and flow angularity contours in the symmetry plane of the test section obtained from using the Baldwin-Barth turbulence model. Again the same procedure is used to determine the effective flow angularity, and evaluate how well $\alpha_{u p}$ performed. The adjoint-based grids are used in this simulation. Additionally, for consistency, the free-air case is run with the same turbulence model (Baldwin-Barth). The same normalizations are applied to the results, which are shown in figure 29. It seems with the thinner boundary layer (figure 19, the non-uniform flow angularity effects has a larger impact on axial force and pitching moment, as the errors are 2.5x greater than the SA turbulence model results. Note: figure 29's values for normal, axial, and pitch coefficient are rescaled by arbitrary numbers to make it ITAR free. 


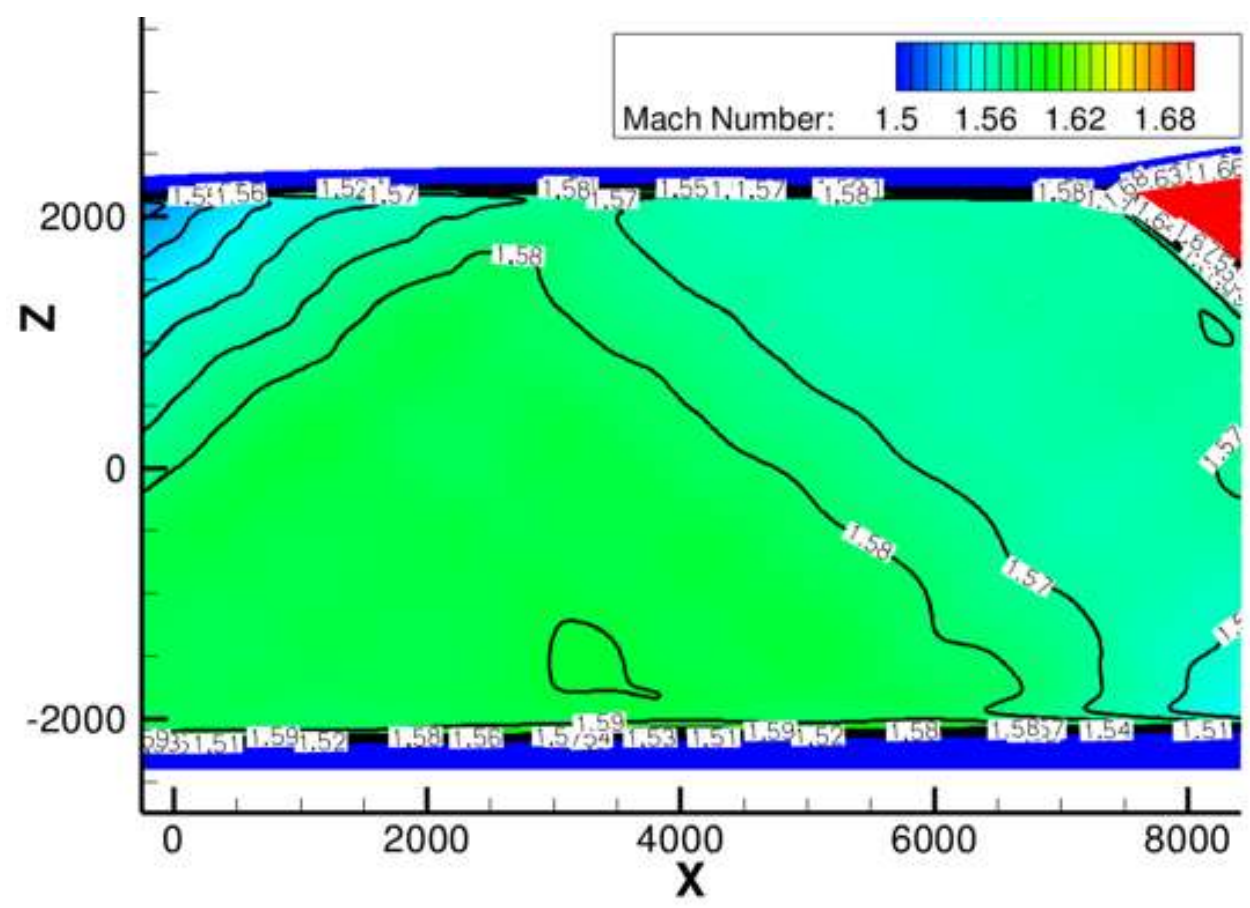

Figure 27: Mach Contours of UPWT Test Section 1 at Mach 1.6, Baldwin-Barth Turbulence Model

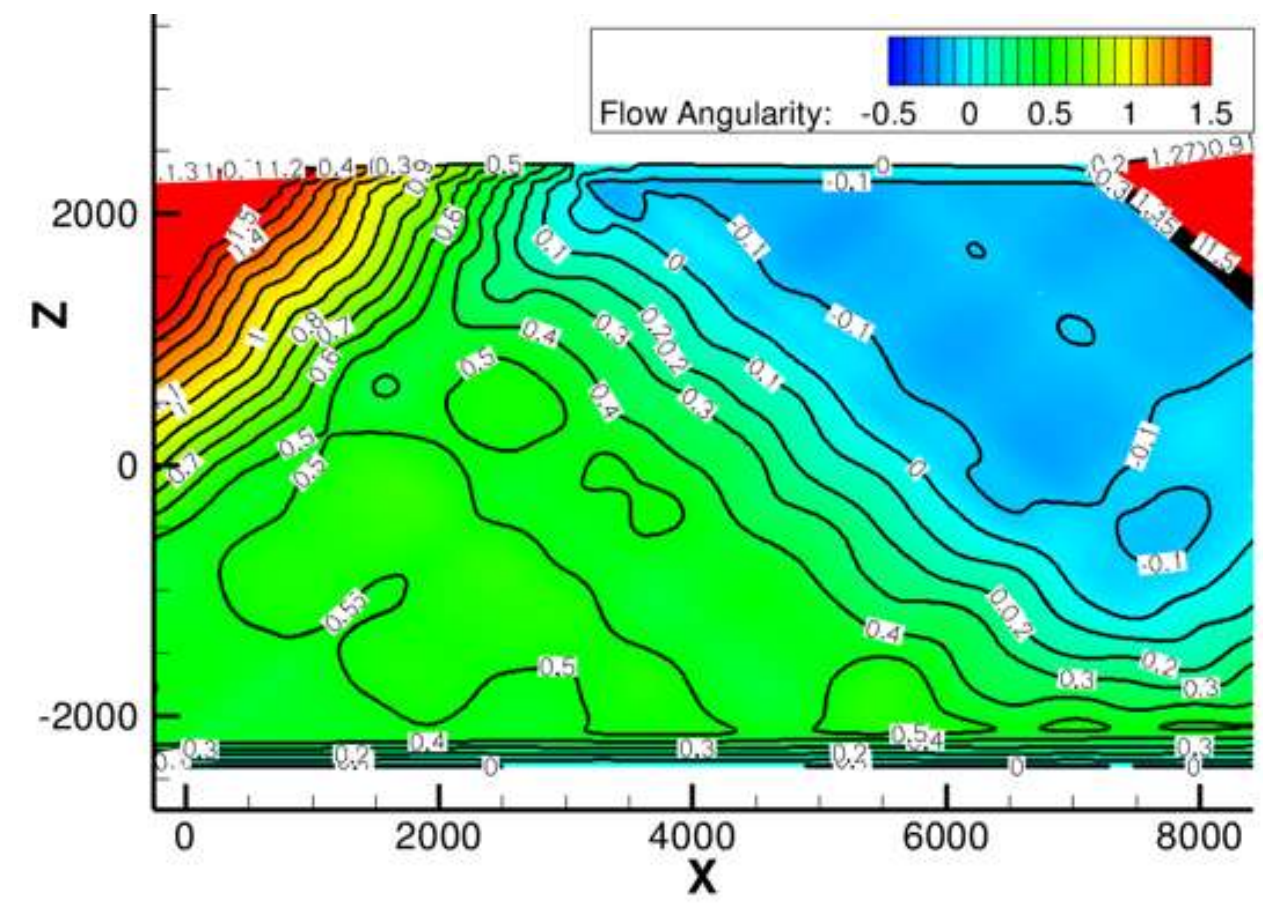

Figure 28: Computed Flow Angularity of UPWT Test Section 1 at Mach 1.6, Baldwin-Barth Turbulence Model 


\begin{tabular}{|c|c|c|c|c|c|c|c|c|}
\hline & Nom a & $\operatorname{Corr} \alpha$ & Mach & $\mathrm{C}_{\mathrm{N}}$ & $\mathrm{C}_{\mathrm{A}}$ & Corr-Pitch (Y) & Effective $a_{u p}$ & $\Delta \mathrm{Cmy}$ \\
\hline M1.6 & & & & & & & -0.2683 & 0.4035 \\
\hline tunnel & 2 & 2.0000 & 1.6 & 0.2720 & 1.8096 & 9.1206 & & \\
\hline tunnel & -2 & -2.0000 & 1.6 & -0.2077 & 1.7857 & -6.2581 & & \\
\hline tunnel & 7 & 6.7317 & 1.6 & 0.7224 & 1.9797 & 26,1202 & & \\
\hline tumnel & -7 & -7.2683 & 1.6 & -0.6986 & 1.9755 & -25.4942 & & \\
\hline no tumnel (nt) & 7 & 7.0000 & 1.6 & 0.7114 & 1.9795 & 25.8937 & & \\
\hline$\%$ error 7 to -7 & & & 1.6 & 3.3379 & 0.2098 & 2.4176 & & \\
\hline$\%$ error 7 to nt & & & 1.6 & 1.5353 & 0.0100 & 0.8747 & & \\
\hline$\%$ error -7 to $\mathrm{nt}$ & & & 1.6 & -1.8026 & -0.1998 & -1.5429 & & \\
\hline & & & & & & & & \\
\hline M1.6 refined & & & & & & & -0.2638 & 1.3803 \\
\hline tumnel & 2 & 2.0000 & 1.6 & 0.2723 & 1.8214 & 10.6404 & & \\
\hline tunne] & -2 & -2.0000 & 1.6 & -0.2088 & 1.7927 & -5.7440 & & \\
\hline tumnel & 7 & 6.7362 & 1.6 & 0.7260 & 1.9830 & 26.2143 & & \\
\hline tunnel & -7 & -7.2638 & 1.6 & -0.7024 & 1.9802 & -25.6010 & & \\
\hline no tumnel (nt) & 7 & 7.0000 & 1.6 & 0.7144 & 1.9837 & 26.0039 & & \\
\hline$\%$ error 7 to -7 & & & 1.6 & 3.3092 & 0.1423 & 2.3584 & & \\
\hline$\%$ error 7 to nt & & & 1.6 & 1.6249 & -0.0333 & 0.8090 & & \\
\hline$\%$ error -7 to nt & & & 1.6 & -1.6843 & -0.1756 & -1.5494 & & \\
\hline & & & & & & & & \\
\hline $\mathrm{M} 1.6 \mathrm{bb}$ & & & & & & & -0.2698 & 0.0348 \\
\hline tunnel & 2 & 2,0000 & 1.6 & 0.2834 & 1.5553 & 9.4819 & & \\
\hline tumnel & -2 & -2.0000 & 1.6 & -0.2160 & 1.4767 & -7.1667 & & \\
\hline tunnel & 7 & 6.7302 & 1.6 & 0.7940 & 1.8128 & 29.2342 & & \\
\hline tunnel & -7 & -7.2698 & 1.6 & -0.7743 & 1.7968 & -27.4141 & & \\
\hline no tumnel (nt) & 7 & 7.0000 & 1.6 & 0.7855 & 1.8000 & 28.4576 & & \\
\hline$\%$ error 7 to -7 & & & 1.6 & 2.5047 & 0.8864 & 6.3957 & & \\
\hline$\%$ error 7 to nt & & & 1.6 & 1.0801 & 0.7119 & 2.7288 & & \\
\hline$\%$ oerror -7 to $n t$ & & & 1.6 & -1.4245 & -0.1745 & -3.6668 & & \\
\hline
\end{tabular}

Figure 29: Comparison of Induced Errors for Mach 1.6 configuration, original grid, adjoint grid, and different turbulence models.

\section{Summary of Procedure}

This section gives a brief outline of the procedure used to correct for the tunnel effects on the reported wind tunnel data. An attempt is made to follow the standard wind tunnel data reduction technique used to eliminate test section inlet flow non-uniformities and flow angularity effects on the angle of attack.

1. Compute grid system in free air at $\alpha=\alpha_{\text {nom }}$ for clean DAC1 configuration.

2. Compute solution in free air at $\alpha=\alpha_{\text {nom }}$.

3. Compute grid system for empty tunnel with entire inlet section and test section.

4. Compute solution in empty tunnel.

5. Compare flow non-uniformities and boundary layer thickness with experimental data from Calibration report ${ }^{1}$. 
6. Install free air grid system in tunnel at $\alpha= \pm 2^{\circ}$.

7. Determine effective (or integrated) flow angularity $\left(\alpha_{u p}\right)$.

8. Install free air grid system in tunnel at $\alpha \pm \alpha_{u p}$.

9. Compare integrated forces $\left(C_{N}\right)$ at $\alpha= \pm 7+\alpha_{u p}$ with free air forces at $\alpha=7^{\circ}$.

10. Differences are the wind tunnel errors in $C_{N}$ due to the test section flow non-uniformities and tunnel wall effects.

11. Correct wind tunnel data in $C_{N}$ for the wind tunnel errors.

12. $C_{m y}$ may not be zero at $\alpha=\alpha_{u p}$ (flow angularity correction for $C_{N}$ ). Compute the additional correction to $C_{m y}$ to force $\left(C_{m y}+\Delta C_{m y}\right)=0$ at $\alpha=\alpha_{u p}$.

13. Correct wind tunnel data in $C_{m y}$ (ie. shift by $\Delta C_{m y}$ ).

14. No additional correction beyond the $\alpha_{u p}$ is applied to $C_{A}$.

15. Do not correct for side forces $\left(C_{y}\right)$, no way of doing this.

16. Use corrected wind tunnel data to validate the CFD solutions.

17. Rationale:

(a) Same grid system around the DAC1 configuration and same turbulence model, flow solver, boundary conditions, and convergence levels are used for all five runs for each case.

(b) Because of (a), the effects of the CFD uncertainties are removed and the increments (errors) can be used to correct the reported wind tunnel data. Any other effects in the CFD data will be due to the flow non-linearities between $\alpha$ and $\alpha+\alpha_{u p}$.

18. Add uncertainty bounds due to the tunnel Mach number uncertainties. For example the calibration report indicates that the uncertainty of the measured Mach number is \pm 0.01 .

\section{Summary}

This procedure has shown that it is possible to remove some of the systematic uncertainty from the wind tunnel data by the use of numerical simulations to compute the discrepancies between the tunnel results and free air results. The technique is fairly compute-intensive, requiring four complete simulations for each set of flow parameters. However only a limited number of cases need to be corrected to show the extent of the required corrections. In the example shown above the systematic error or discrepancy between the CFD and wind tunnel data has been reduced from more than $5 \%$ to less than $3 \%$. There is still an error larger than $3 \%$ at Mach 1.6. This Mach number needs further investigation. The accuracy of using numerical simulation to capture the test section inflow state needs to be ascertained. Unfortunately the calibration report has limited data on the inlet flow state. ${ }^{1}$

With more of the tunnel artifacts removed from the wind tunnel data, the corrected wind tunnel data are a much more appropriate experimental data set for validating CFD data. Typically the CFD data is for free-air flow fields and wind tunnel data are not. Much of the systematic errors in wind tunnel data are due tunnel effects, either walls or non-uniform inlet flow fields. Current wind tunnel data reduction techniques do not seem to eliminate all of the tunnel artifacts from the data. The proposed technique provides a method to further reduce tunnel artifacts from the wind tunnel data.

The method needs to be tested for other force and moment coefficients, in particular the roll moment coefficient for CLV configurations with protuberances. The roll moments are believed to be especially sensitive to tunnel artifacts such as flow non-uniformities and variable flow angularity angles.

\section{Acknowledgments}

The help provided by the following is greatly appreciated: Sam Walton, William Chan, James Kless, and Jasim Ahmad. 


\section{References}

${ }^{1}$ Jackson, Charlie M. Jr., Corlett, William A., and Monta, William J., "Description and Calibration of the Langley Unitary Plan Wind Tunnel," NASA LaRC TP-1905, Hampton, VA 1981.

${ }^{2}$ P. G. Buning, D. C. Jespersen, T. H. Pulliam, G. H. Klopfer, W. M. Chan, J. P. Slotnick, S. E. Krist, and K. J. Renze, OVERFLOW Users Manual, NASA Unpublished Report, 2005.

${ }^{3}$ Nichols, Robert., Tramel, Robert., and Buning, Pieter., "Solver and Turbulence Model Upgrades to OVERFLOW 2 for Unsteady and High-Speed Applications," AIAA Paper 2006-2824, 24th AIAA Applied Aerodynamics Conference, San Francisco, CA, June 2006.

${ }^{4}$ Spalart, P.R., and Allmaras, S.R., " A One-Equation Turbulence Model for Aerodynamic Flows," AIAA Paper 92-0439, 29th AIAA Aerospace Sciences Meeting, Reno, NV, Jan 1992.

${ }^{5}$ Wilcox, Floyd J., "0.01-Scale CLV DAC-1 Unitary Plan Wind Tunnel Test 1958," Unpublished NASA LaRC Report, Langley Research Center, VA, July 2006.

${ }^{6}$ Micol, John R., "Langley Research Center's Unitary Plan Wind Tunnel: Testing Capabilities and Recent Modernization Activities," AIAA Paper 2001-0456, 39th AIAA Aerospace Sciences Meeting, Reno, NV, Jan 2001.

${ }^{7}$ Nemec, M.N., and Aftosmis, M.J., "Adjoint error estimation and adaptive refinement for embedded-boundary Cartesian meshes," AIAA Paper 2007-4187, 18th AIAA Computational Fluid Dynamics Conference, Miami, FL, June 2007.

${ }^{8}$ Baldwin, B.S., and Barth, T.J., "A One-Equation Turbulence Transport Model for High Reynolds Number Wall-Bounded Flows," AIAA Paper 91-0610, 29th AIAA Aerospace Sciences Meeting, Reno, NV, Jan. 1991.

${ }^{9}$ Chan, William., "The OVERGRID Interface for Computational Simulations on Overset Grids," AIAA Paper 2002-3188, 32nd AIAA Fluid Dynamics Conference and Exhibit, St. Louis, MO, June 2002. 


\section{Appendix}

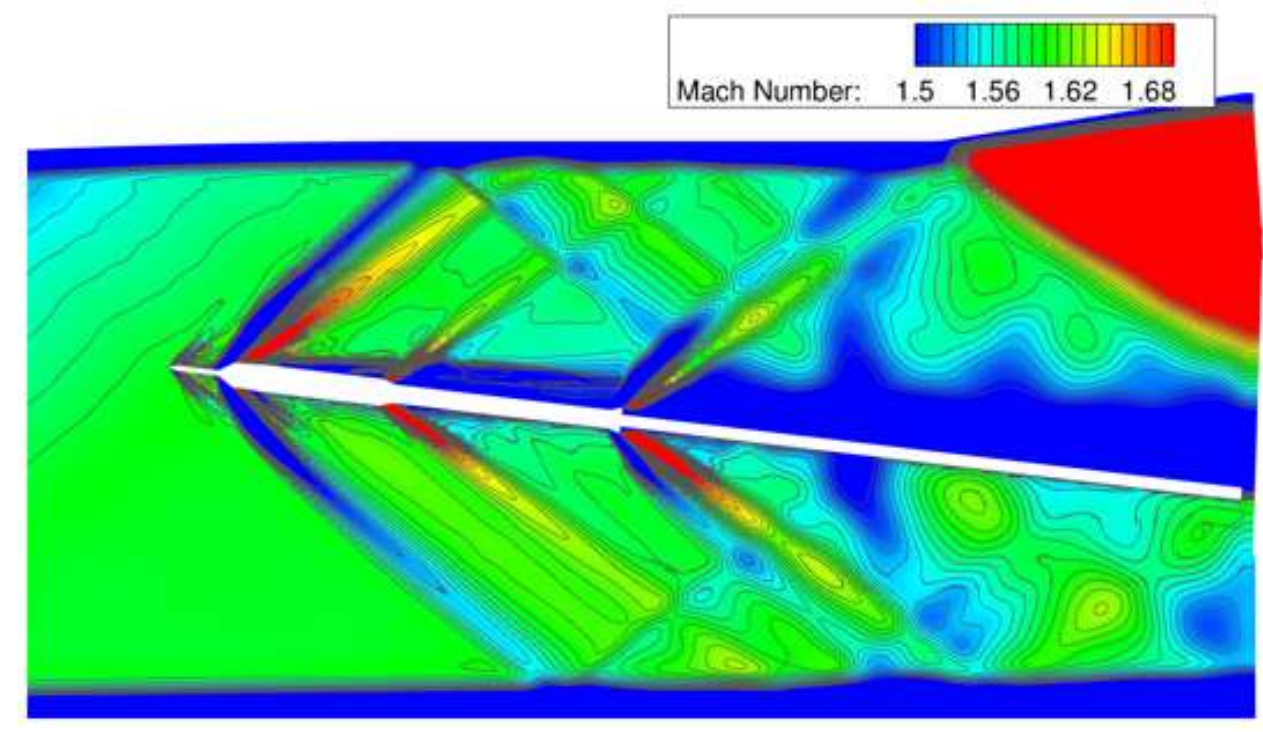

Figure 30: Mach Contours for Tunnel 1 Mach 1.6 configuration at $+7^{\circ}$ AOA

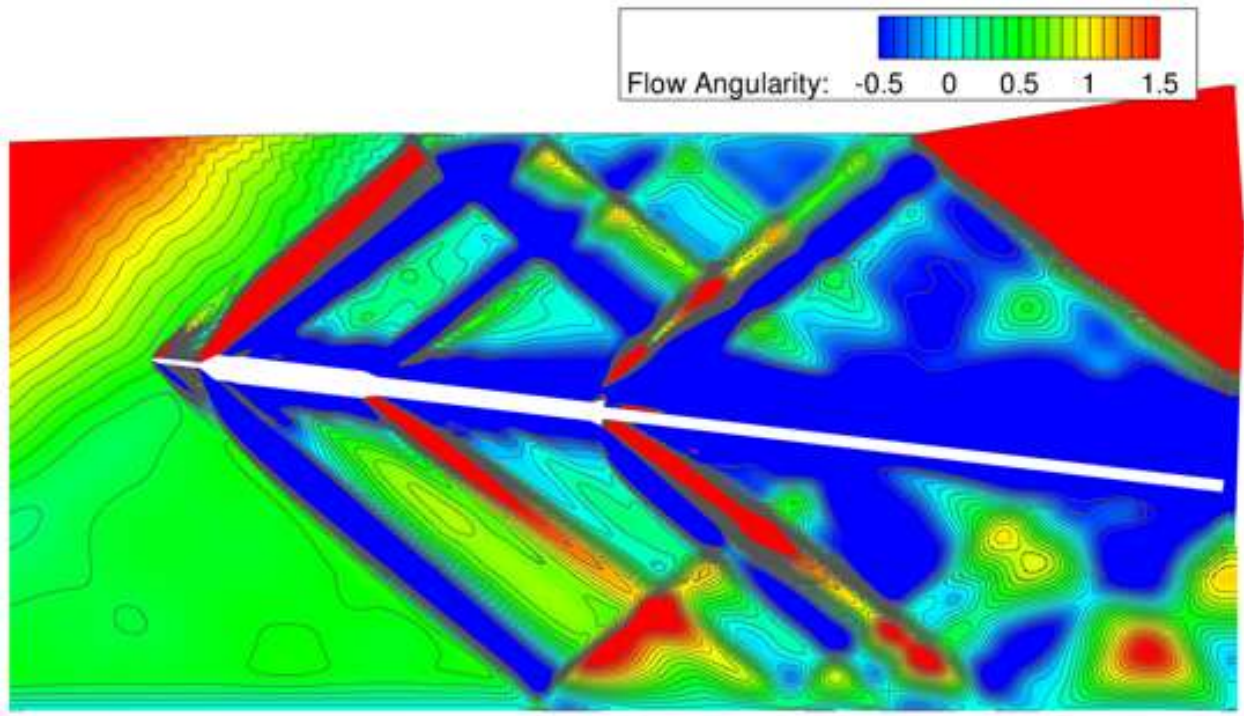

Figure 31: Flow Angularity Contours for Tunnel 1 Mach 1.6 configuration at $+7^{\circ}$ AOA 


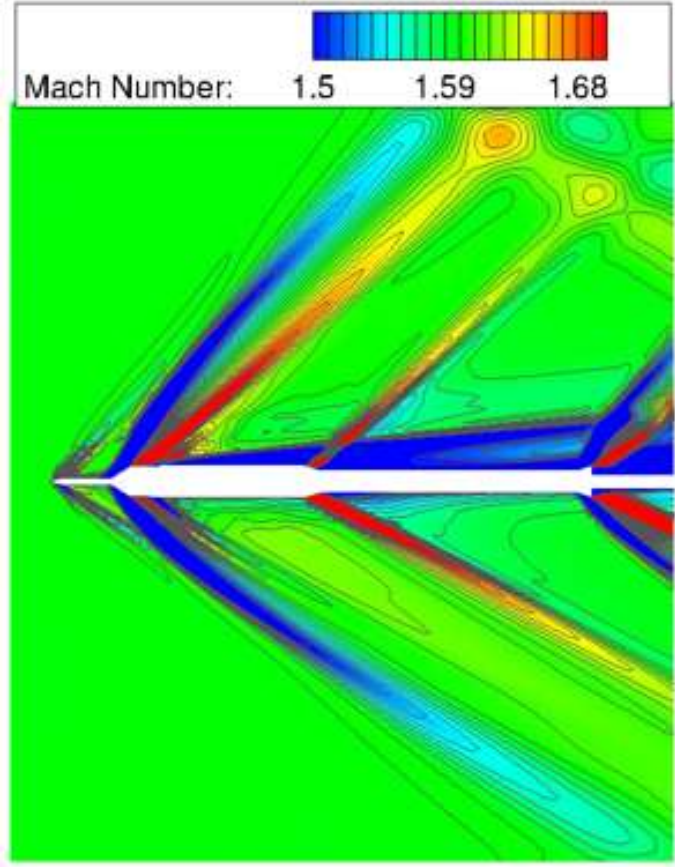

Figure 32: Mach Contours for Mach 1.6 Free Air configuration at $+7^{\circ}$ AOA

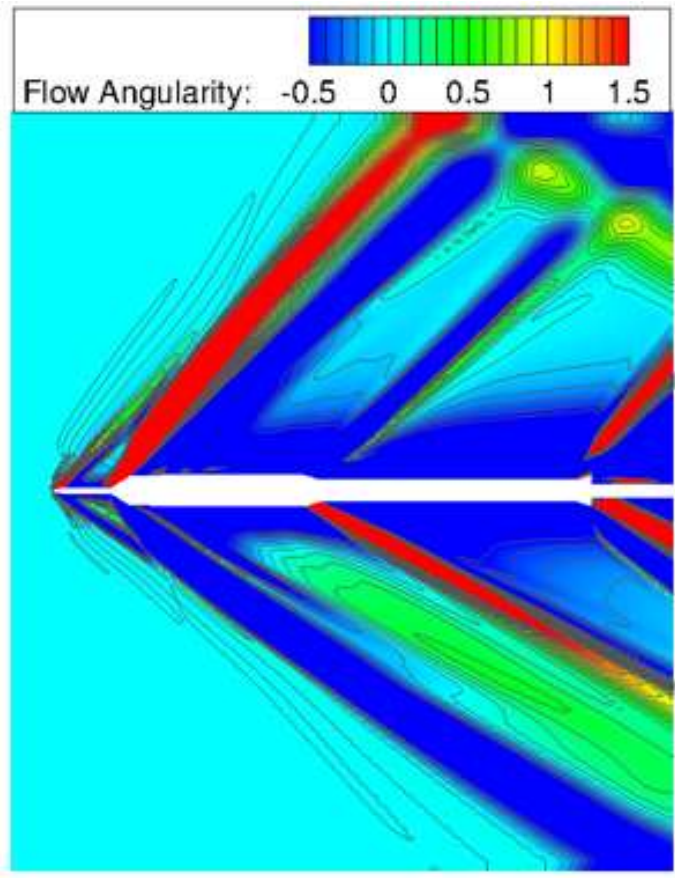

Figure 33: Flow Angularity Contours for Mach 1.6 Free Air configuration at $+7^{\circ}$ AOA 


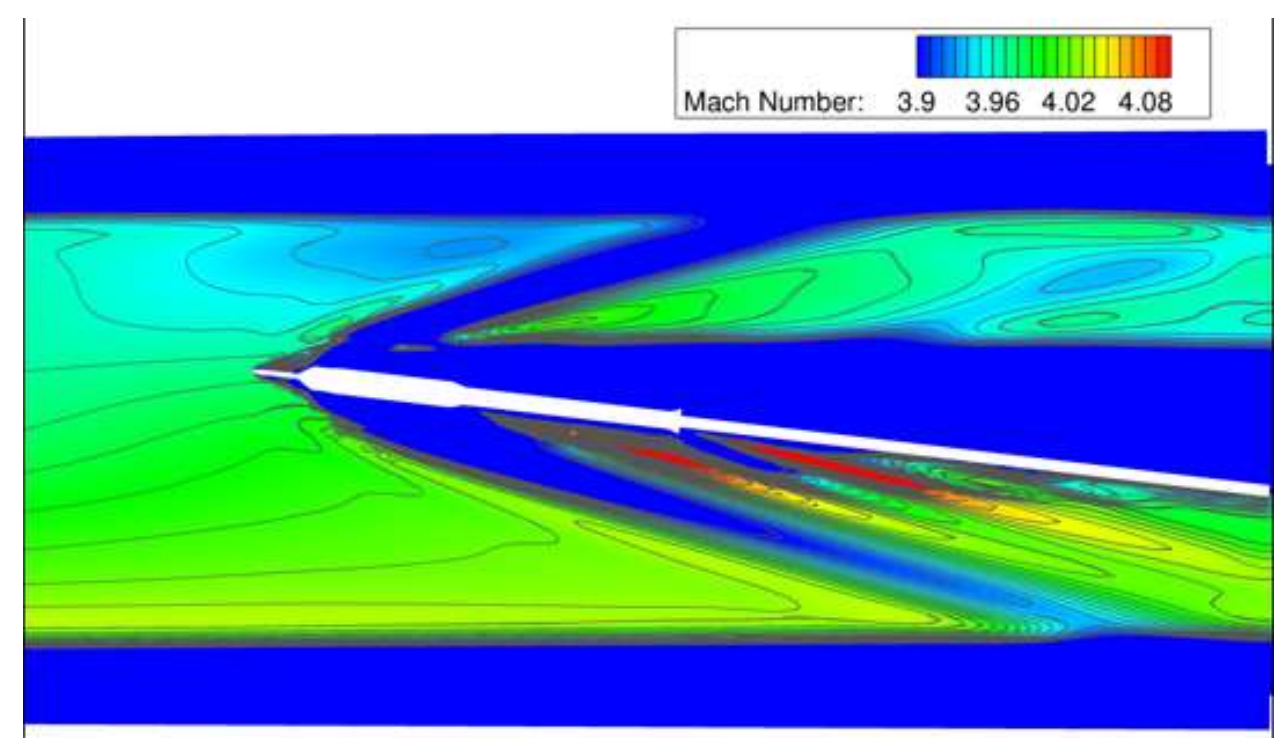

Figure 34: Mach Contours for Tunnel 2 Mach 4 configuration at $+7^{\circ}$ AOA

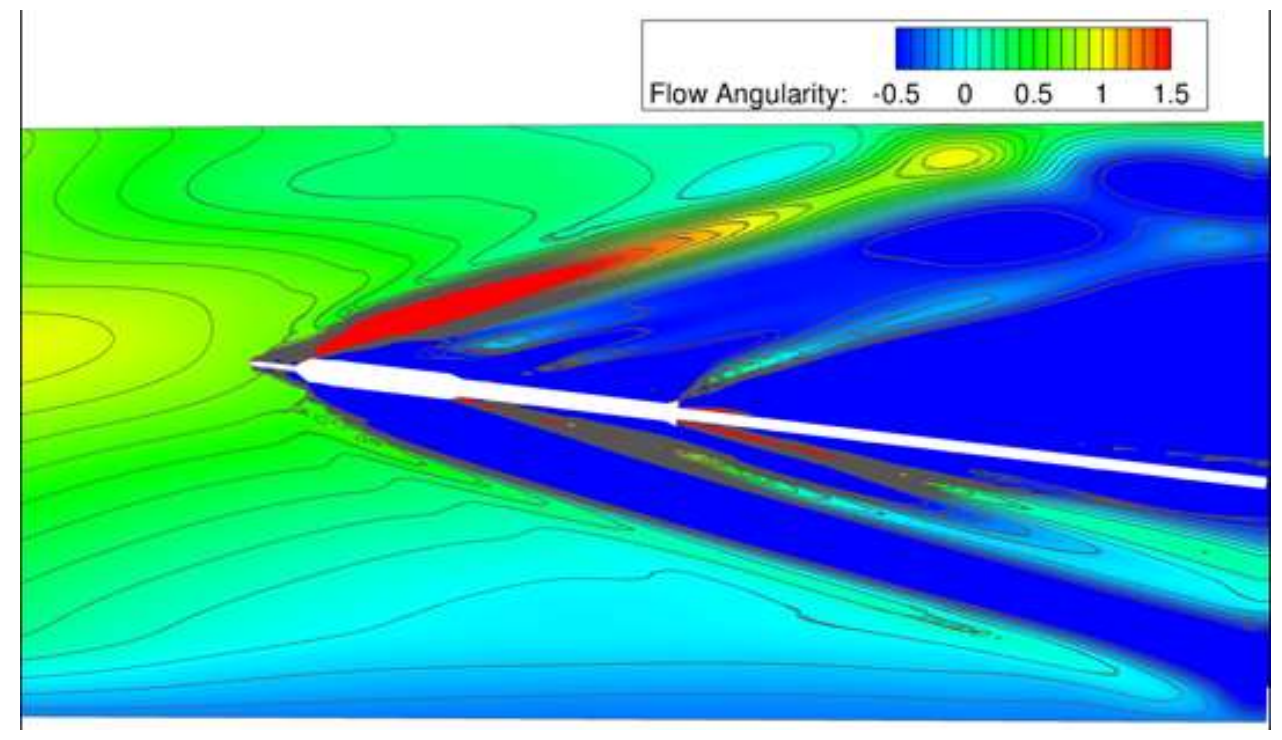

Figure 35: Flow Angularity Contours for Tunnel 2 Mach 4 configuration at $+7^{\circ}$ AOA 


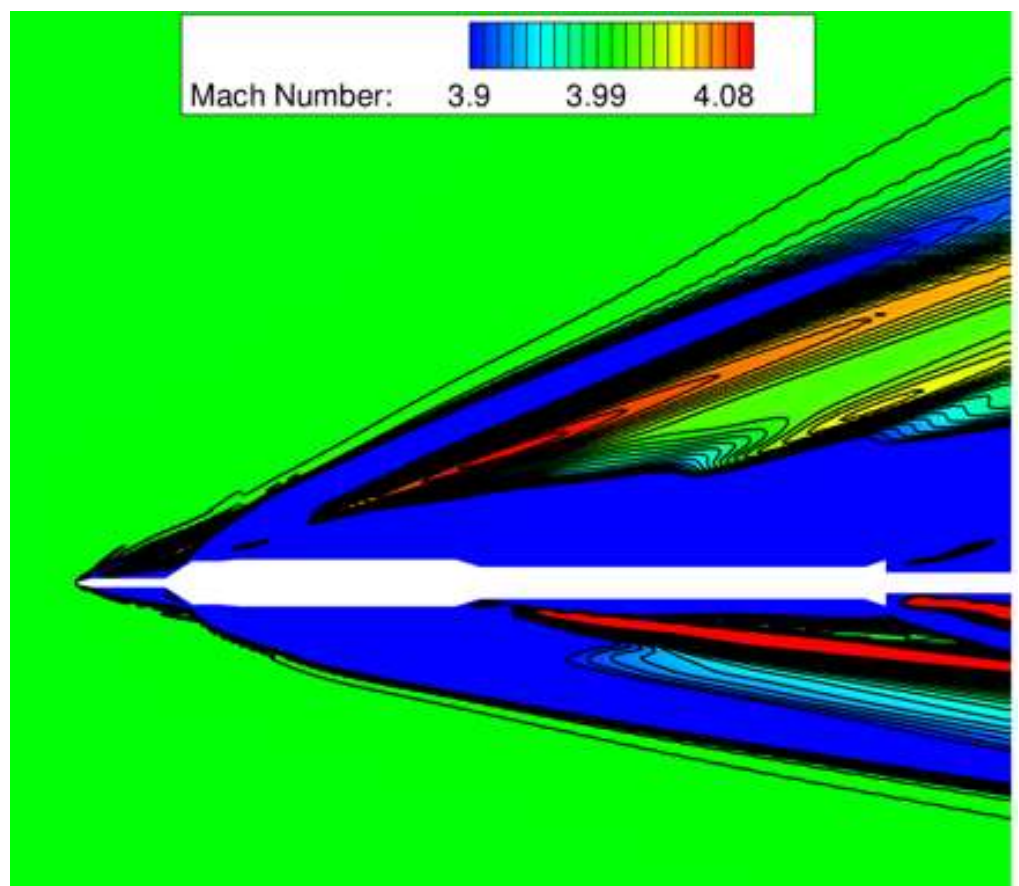

Figure 36: Mach Contours for Mach 4.0 Free Air configuration at $+7^{\circ}$ AOA

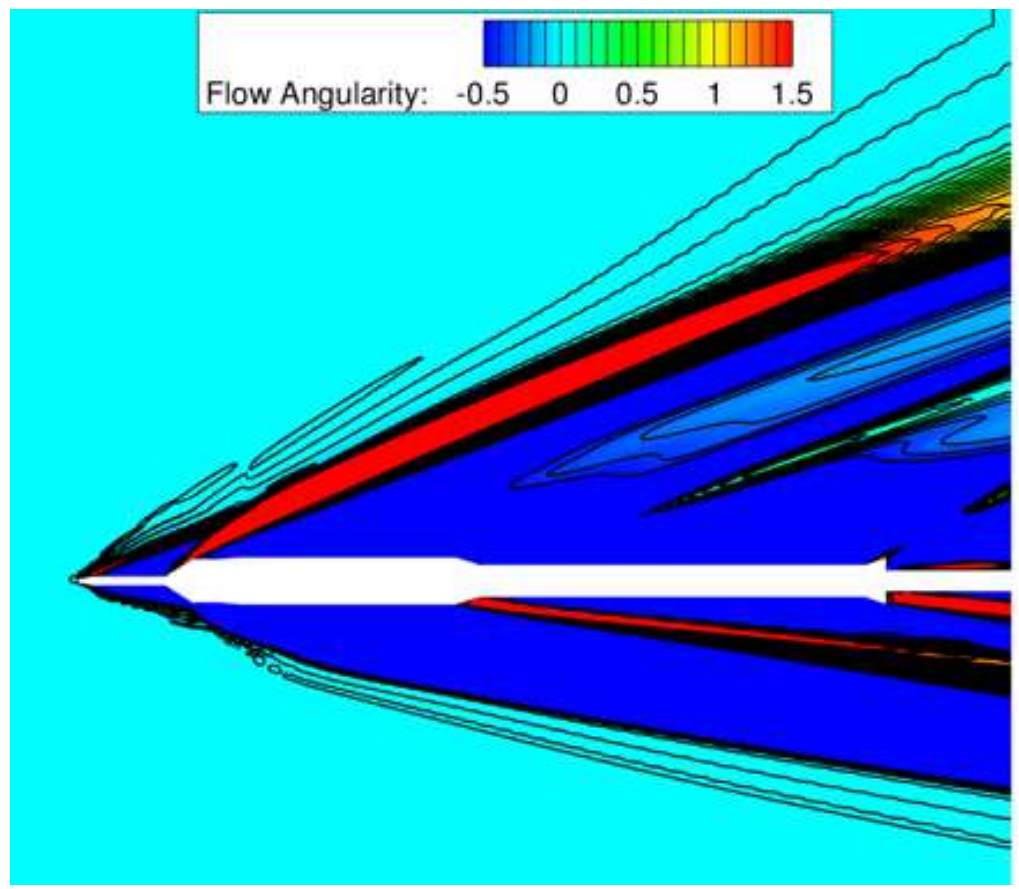

Figure 37: Flow Angularity Contours for Mach 4.0 Free Air configuration at $+7^{\circ}$ AOA 


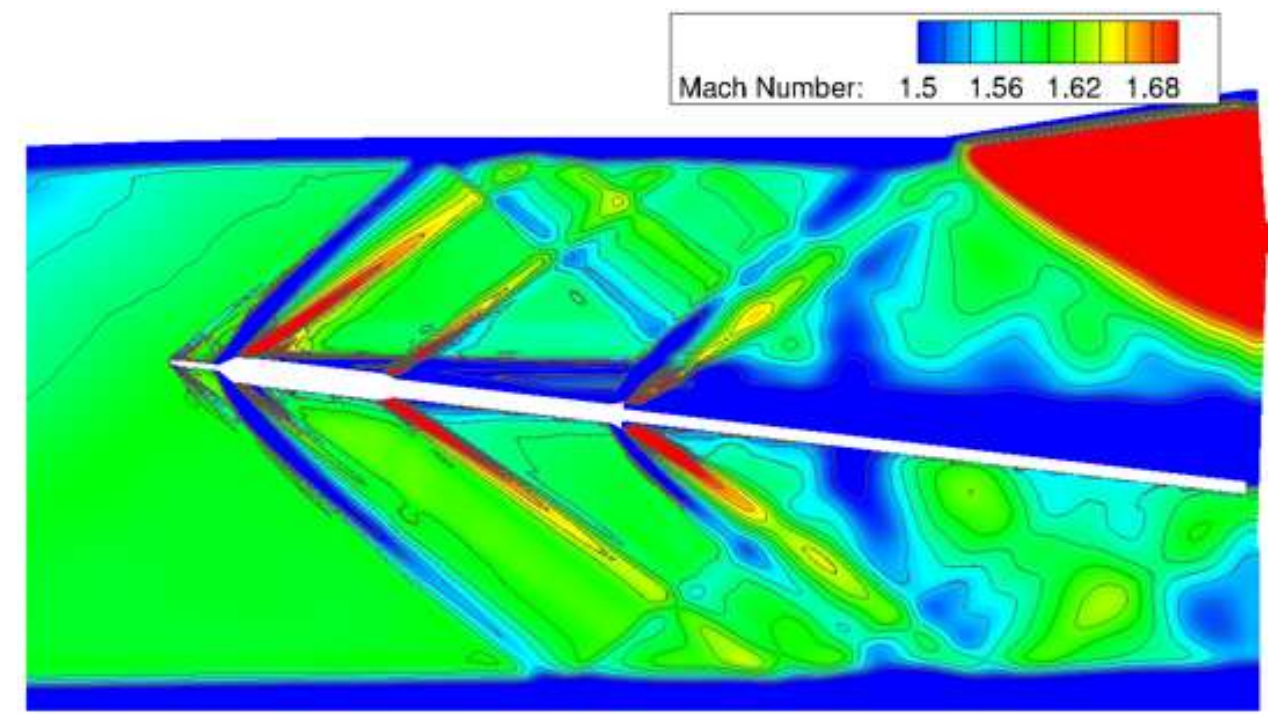

Figure 38: Mach Contours for Tunnel 1 Mach 1.6 configuration at $+7^{\circ}$ AOA, Adjoint-Based Grid

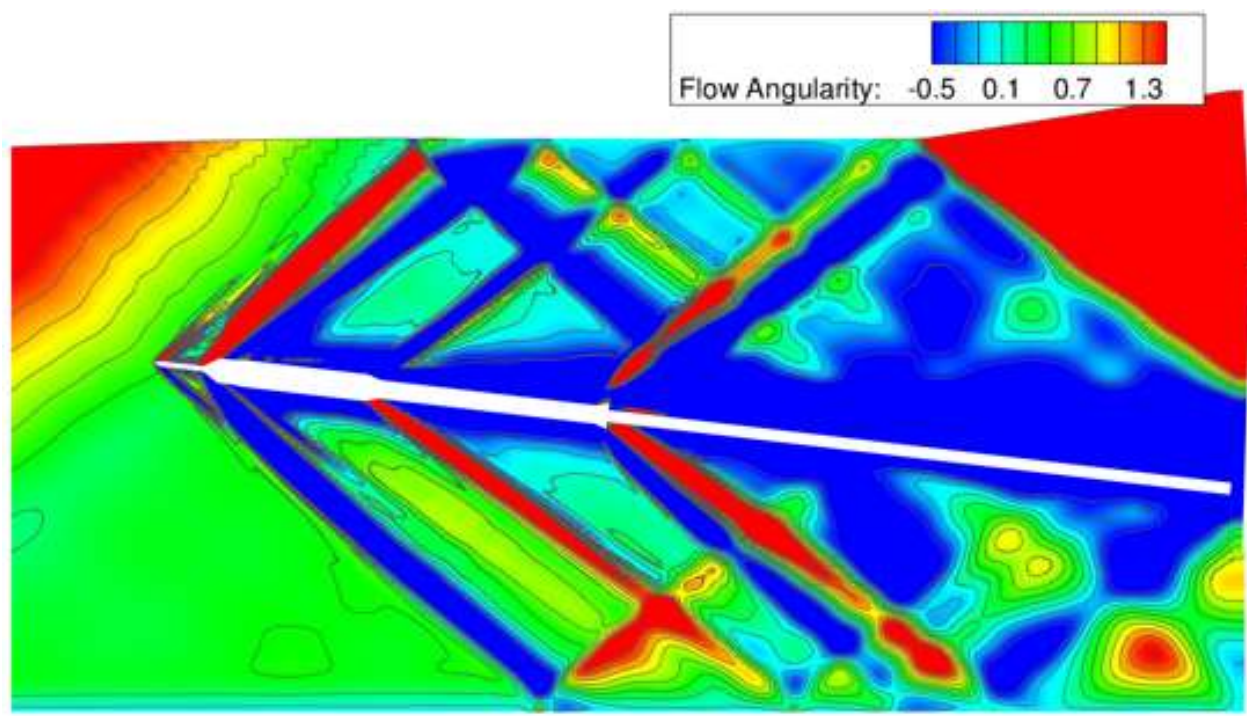

Figure 39: Flow Angularity Contours for Tunnel 1 Mach 1.6 configuration at $+7^{\circ}$ AOA, Adjoint-Based Grid 


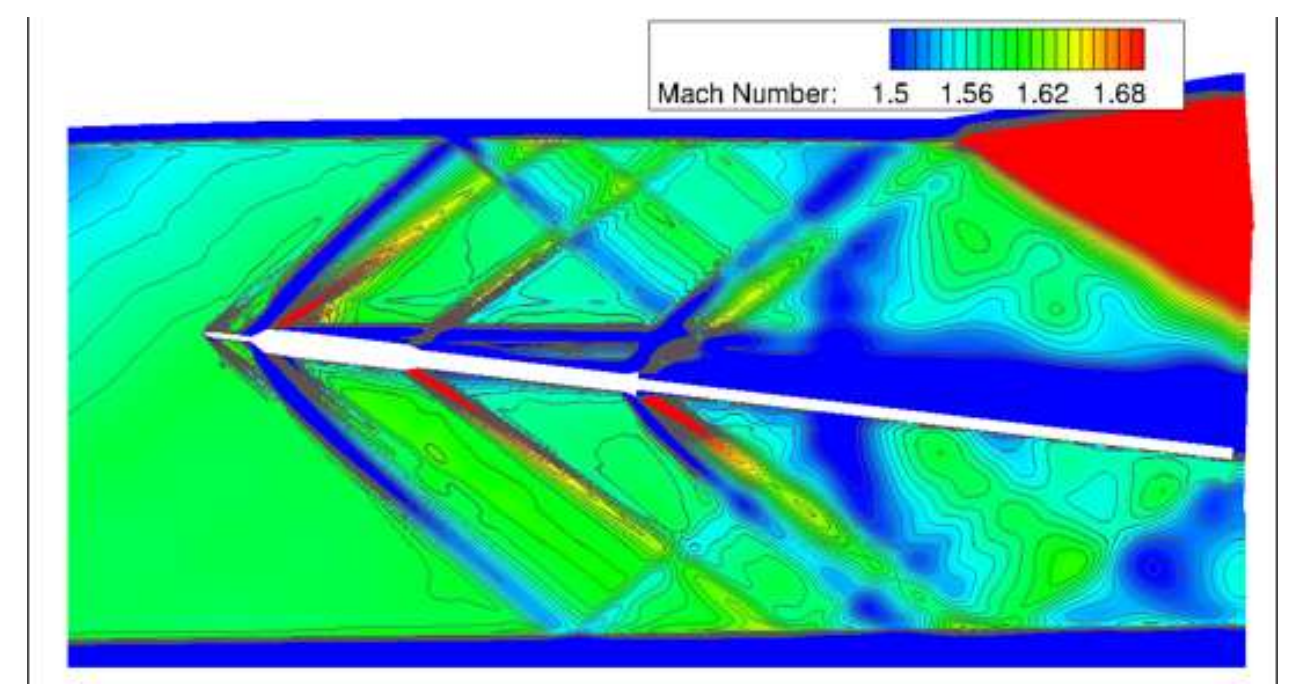

Figure 40: Mach Contours for Tunnel 1 Mach 1.6 configuration at $+7^{\circ}$ AOA, Baldwin-Barth Turbulence Model

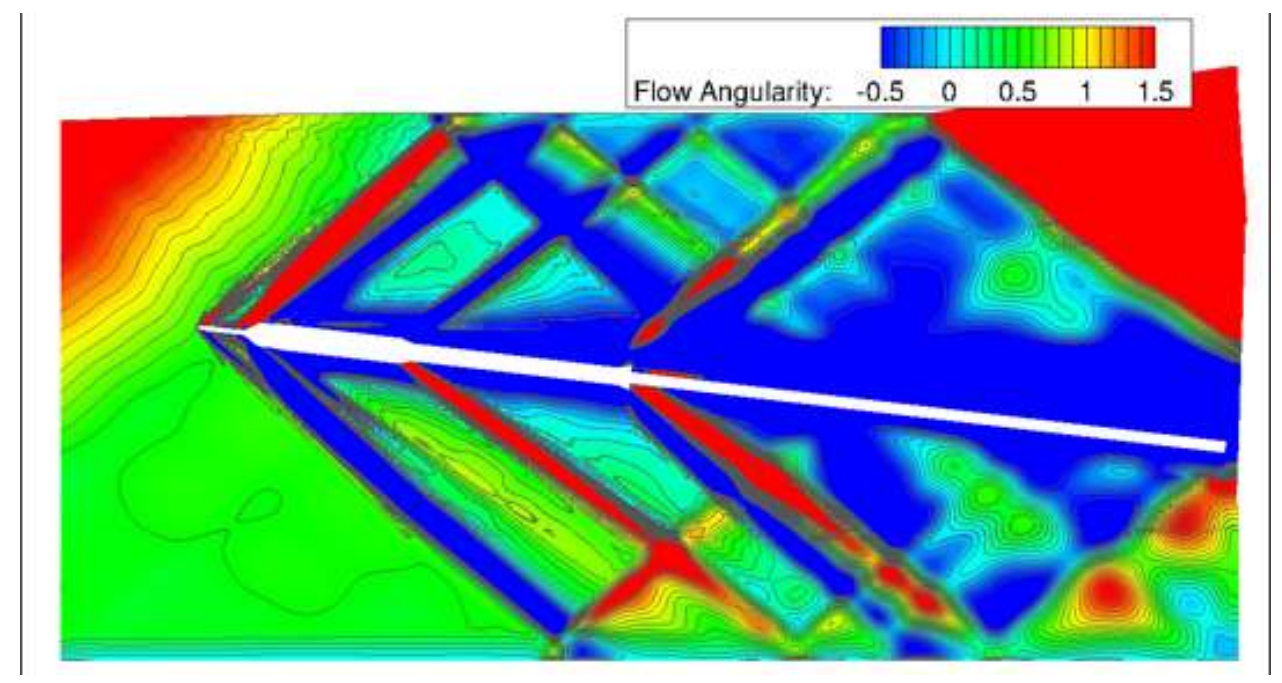

Figure 41: Flow Angularity Contours for Tunnel 1 Mach 1.6 configuration at $+7^{\circ}$ AOA, Baldwin-Barth Turbulence Model 


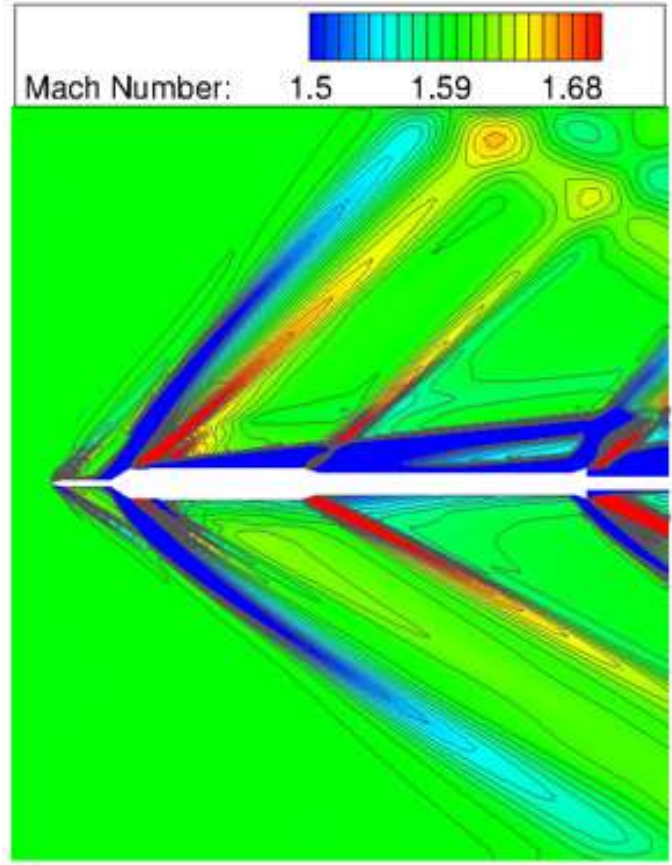

Figure 42: Mach Contours for Mach 1.6 Free Air configuration at $+7^{\circ}$ AOA, Baldwin-Barth Turbulence Model

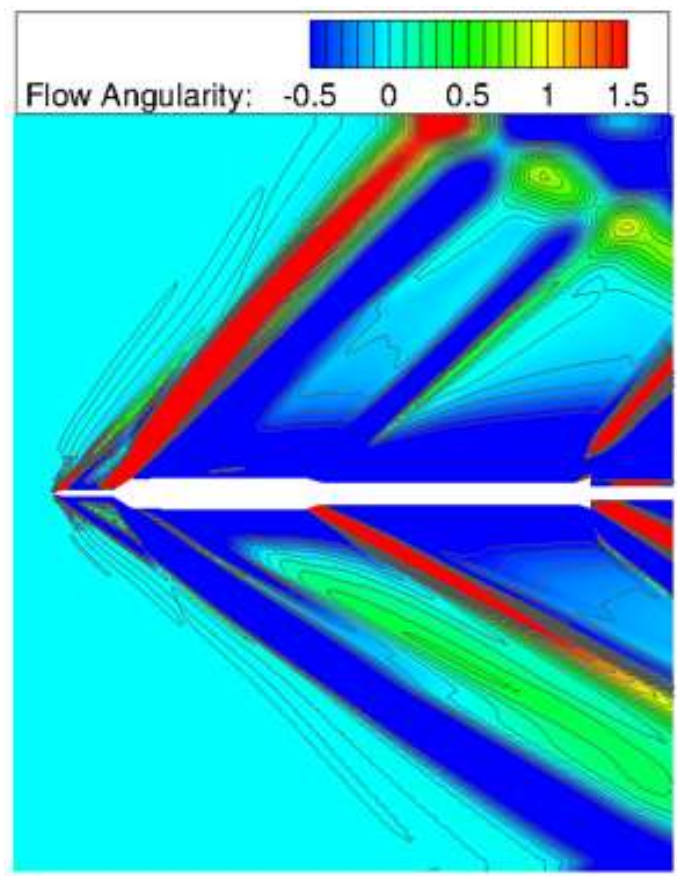

Figure 43: Flow Angularity Contours for Mach 1.6 Free Air configuration at $+7^{\circ}$ AOA, Baldwin-Barth Turbulence Model 


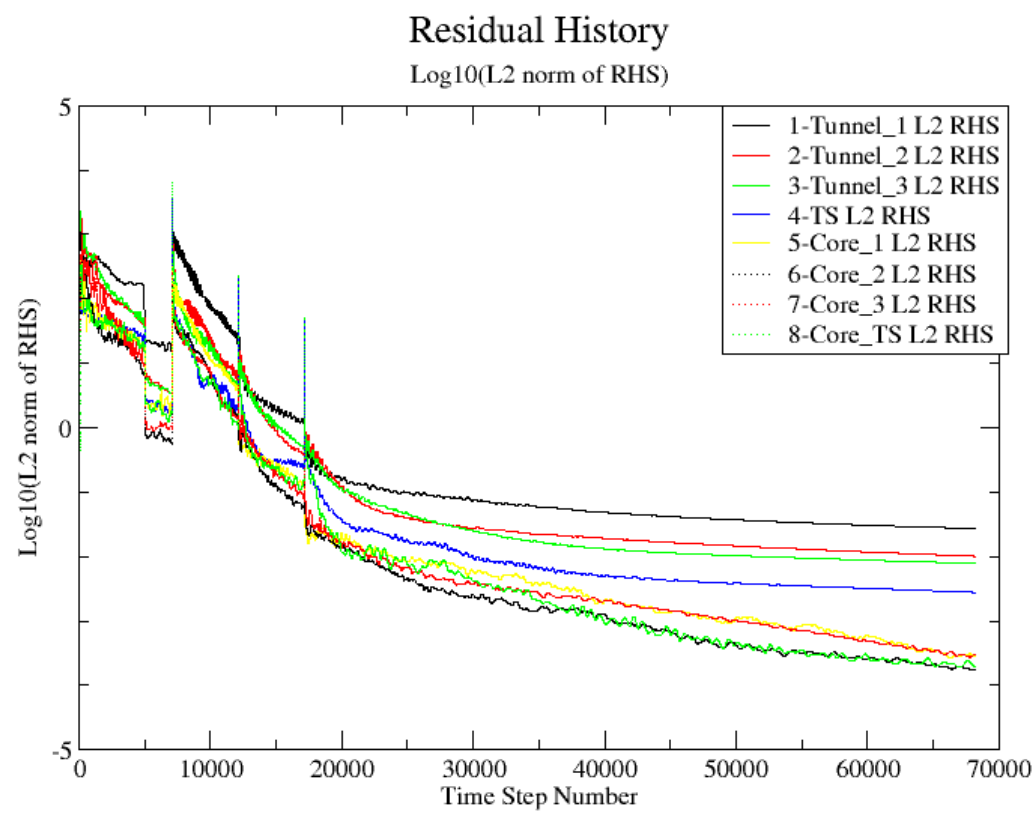

Figure 44: Typical Residual for Full Tunnel simulation

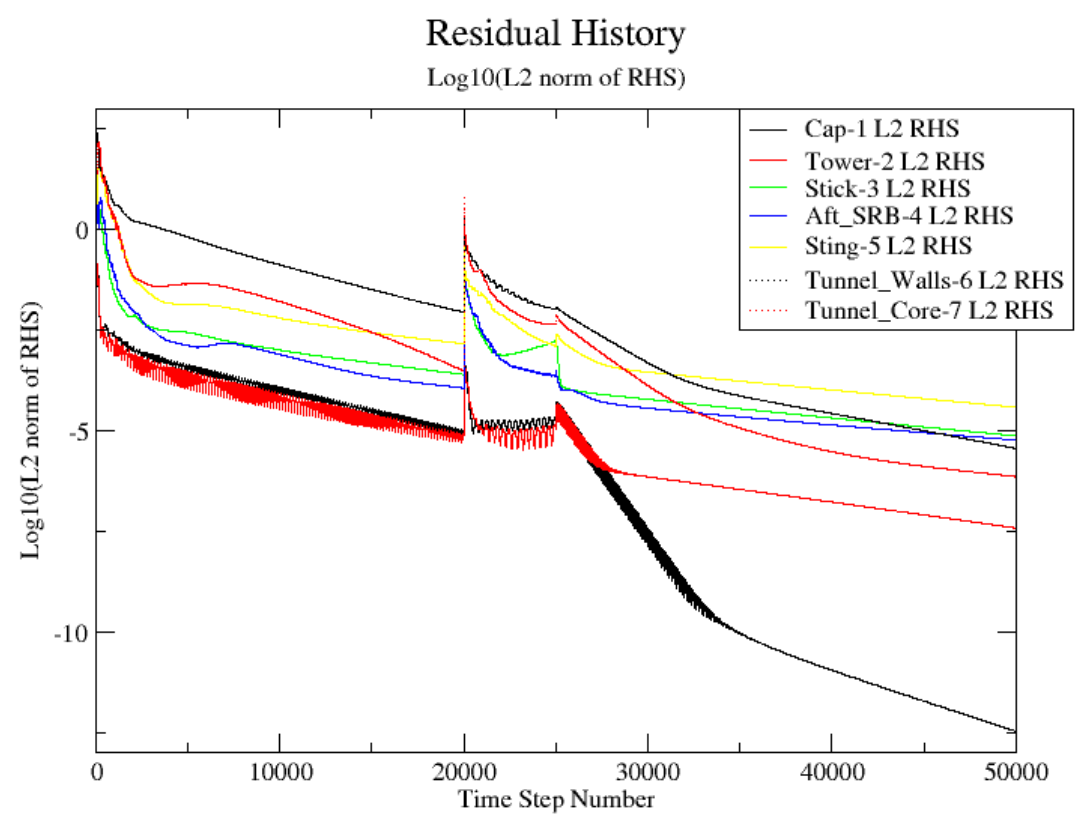

Figure 45: Typical Residual for +7 AOA Tunnel simulation 